Check for updates

Cite this: RSC Adv., 2020, 10, 43733

\title{
Zeolitic imidazolate framework (ZIF)-derived porous carbon materials for supercapacitors: an overview
}

\author{
Rabia Ahmad, (D) a Usman Ali Khan, (D) a Naseem lqbal (D) *a and Tayyaba Noor ${ }^{\text {b }}$
}

The present analysis focuses on the synthetic methods used for the application of supercapacitors with various mysterious architectures derived from zeolitic imidazolate frameworks (ZIFs). ZIFs represent an emerging and unique class of metal-organic frameworks with structures similar to conventional aluminosilicate zeolites, consisting of imidazolate linkers and metal ions. Their intrinsic porous properties, robust functionalities, and excellent thermal and chemical stabilities have resulted in a wide range of potential applications for various ZIF materials. In this rapidly expanding area, energetic research activities have emerged in the past few years, ranging from synthesis approaches to attractive applications of ZIFs. In this analysis, the development of high-performance supercapacitor electrodes and recent strategies to produce them, including the synthesis of various heterostructures and nanostructures, are analyzed and summarized. This analysis goes via the ingenuity of modern science when it comes to these nanoarchitecture electrodes. Despite these significant achievements, it is still difficult to accurately monitor the morphologies of materials derived from metal-organic frameworks (MOFs) because the induction force during structural transformations at elevated temperatures is in high demand. It is also desirable to achieve the direct synthesis of highly functionalized nanosized materials derived from zeolitic imidazolate frameworks (ZIFs) and the growth of nanoporous structures based on ZIFs encoded in specific substrates for the construction of active materials with a high surface area suitable for electrochemical applications. The latest improvements in this field of supercapacitors with materials formed from ZIFs as electrodes using ZIFs as templates or precursors are discussed in this review. Also, the possibility of usable materials derived from ZIFs for both existing and emerging energy storage technologies is discussed.

Received 7th October 2020

Accepted 13th November 2020

DOI: $10.1039 / \mathrm{dOra08560j}$

rsc.li/rsc-advances

\section{Introduction}

In addition to batteries, supercapacitors are relatively new devices that are capable of producing high power rates. Although supercapacitors deliver thousands of times more power than batteries, they cannot hold the same amount of charge as batteries, normally 3-30 times less. Hence, supercapacitors can prove to be ideal for certain applications that need power outbursts, but not those where high energy storage capacity is required. ${ }^{1-3}$ Supercapacitors can also be used in battery-based energy storage systems (ESS) to configure their energy and power capabilities, boost the capacity, achieve the energy and power requirements and increase the lifespan.,5

The power output of supercapacitors compared to electrolytic capacitors is very low, while their specific energy is many

${ }^{a}$ US-Pakistan Center for Advanced Studies in Energy (USPCAS-E), National University of Sciences and Technology (NUST), Islamabad 4400o, Pakistan. E-mail: naseem@ uspcase.nust.edu.pk; Tel: +92-51-90855281

${ }^{b}$ School of Chemical and Materials Engineering (SCME), National University of Sciences and Technology (NUST), Islamabad 4400o, Pakistan times higher. ${ }^{3,6}$ Supercapacitors are of interest because they are an improvement over batteries and conventional capacitors, which can store significant quantities of energy at lower power densities $\left(1 \mathrm{~kW} \mathrm{~kg}^{-1}\right)$ due to their storage mechanism. Fig. 1 shows that a battery can provide almost $150 \mathrm{~W} \mathrm{~h} \mathrm{~kg}^{-1}$ of energy density, which is basically around 10 times the capability of an electrochemical capacitor. In terms of energy density, batteries do not have the potential to reach electrochemical capacitor values. Batteries barely reach $200 \mathrm{~W} \mathrm{~kg}^{-1}$, approximately 20 times less than the estimated output of electrochemical capacitors. ${ }^{7,8}$ This is because batteries suffer drawbacks such as a sudden decrease in efficiency due to fast charging cycles or cold ambient temperatures; they are expensive to sustain and have short service lives. ${ }^{2,9}$

However, Ragone plots do not clarify some other key parameters, such as total cost, cycle stability or safety. To obtain a better understanding of the benefits and drawbacks of a certain energy storage technology, these criteria must be described separately.

Hence, this is a very significant factor when considering that supercapacitors are not only able to discharge in a small 


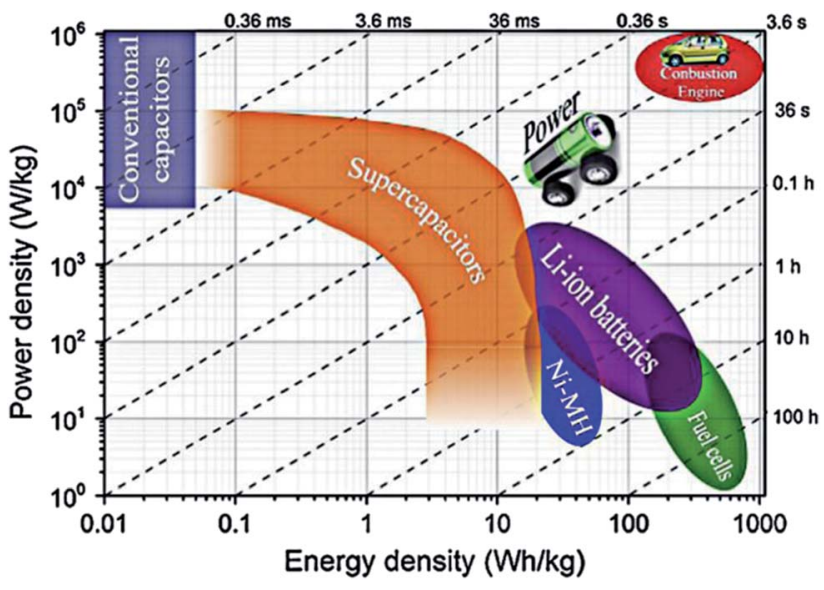

Fig. 1 Ragone plots of different energy storage systems. ${ }^{6}$

amount of time, but can also be charged in a matter of seconds. ${ }^{10}$ The efficiency of supercapacitors has become a significant advantage for energy revival systems, such as 'dynamic braking' for transportation networks. One more key aspect of supercapacitors is their lifespan. Due to their charging storage systems, these devices will run for millions of cycles, in which they store the charges in an electric double layer at the surface of the electrode. ${ }^{11}$ This helps to extend the cycle-life of the batteries. The exceptionally reversible electrostatic charging storage does not affect the volume of the electrode, which removes the bulging that happens during charging/discharging cycles in a normal redox reaction within the bulk of active material of a battery. ${ }^{12}$ Because of the electrochemical kinetics without polarization resistance, supercapacitor electrodes do not have the same drawbacks as redox battery electrodes. The operating voltage of a supercapacitor cell is the primary drawback associated with its charging storage system because it should be kept small to prevent chemical decomposition of the electrolyte. ${ }^{13}$ The trait to note is the range of working temperatures. Also, at $-40{ }^{\circ} \mathrm{C}$, supercapacitors can reach high power outputs, while batteries are currently unable to function at that temperature. ${ }^{4}$ In terms of high power charging and discharging, supercapacitors can also be described as safer than batteries. Electric-double-layer capacitors do not depend on the chemistry of the used metals; therefore, they do not have the risk of metal plating, which is a principal factor in battery degradation and failure and a real security issue which leads to circuit breaks and energetic chemical reactions. ${ }^{2}$

\subsection{Supercapacitors: working principle and types}

Supercapacitors comprise two electrodes with a separator between them, as displayed in Fig. 2. Supercapacitors can be classified as symmetric and asymmetric by the fact that the electrodes in a supercapacitor can be indistinguishable or distinct. The separator is used to avoid electrical contact between the two electrodes during immersion in the electrolyte. The material for the separator should be selected based on high ionic conductivity, low thickness and high electrical resistance to attain the best performance. In general, polymer or paper separators are used for organic electrolytes, whereas ceramic or glass fiber separators are a better alternative for aqueous electrolytes. The breakdown potential of electrolytes at one of the electrodes confines the achievable cell voltage, while the relative series resistance (ESR) of the cell relies on the conductivity of the electrolyte. While the breakdown voltage of aqueous electrolytes is low $(1 \mathrm{~V})$ compared to that of organic electrolytes (3 $\mathrm{v})$, the conductivity required for high-power devices is higher for the former than the latter. Aqueous electrolytes are also costeffective and easy to handle.

Based on their distinct charge storing methods, supercapacitors are categorized into three types, namely electrical double-layer capacitors (EDLCs), pseudo-capacitors (PCs), and hybrid capacitors. ${ }^{15-17}$ These include three main classes for electrode materials: transition metal oxides/hydroxides (TMO/ $\mathrm{Hs}$ ), carbon-based materials, and conducting polymers (CPs), as mentioned in Fig. 2. ${ }^{18,19}$ EDLCs are constructed on the theory of electric-double layers put forward in 1874 by German physicist Helmholtz ${ }^{20}$ and afterward modified by Gouy ${ }^{21}$ in 1957, H. I. Becker demonstrated the operational use of a double-layer capacitor which stores electrostatic energy. ${ }^{13}$ In EDLCs, the energy is stored in the middle of the activated electrode
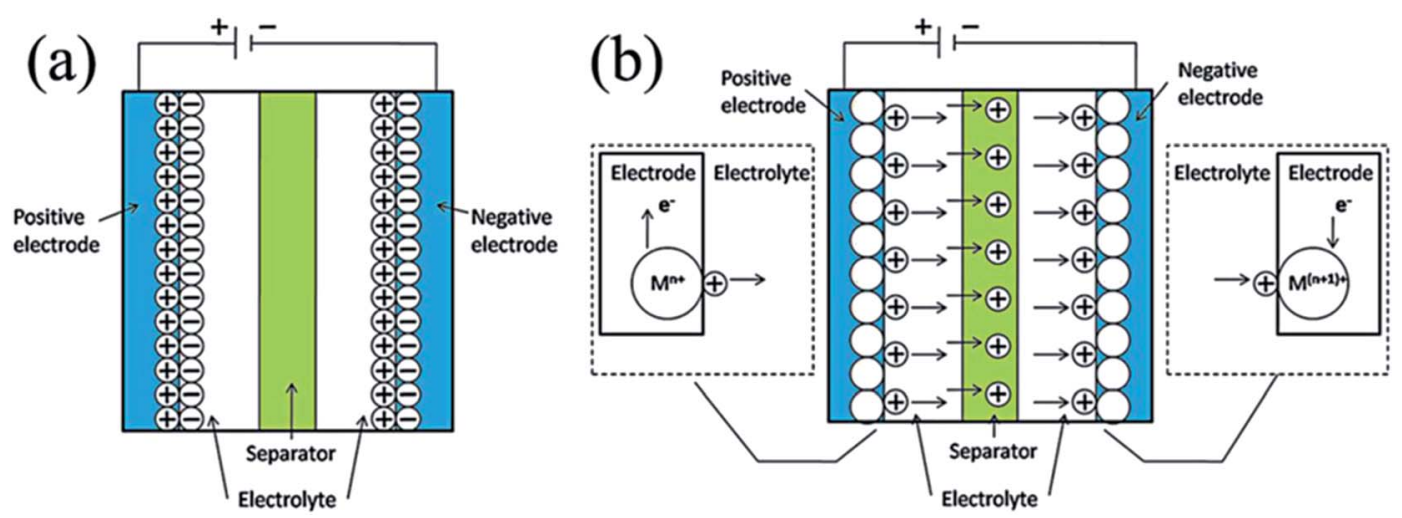

Fig. 2 Representation of various supercapacitors: (a) electrical double-layer capacitors (EDLCs); (b) pseudo-capacitors (PCs) (where M exemplifies a metal atom; if electrolyte anions participate in reversible redox reactions, they move in the opposite route to the cations). ${ }^{14}$ 
Table 1 Comparison of supercapacitor types, electrode materials, and performance parameters

\begin{tabular}{|c|c|c|c|c|}
\hline Supercapacitor types & Reaction process & Materials used as electrodes & Stability & Performance \\
\hline $\begin{array}{l}\text { Electric double-layer } \\
\text { capacitors }\end{array}$ & $\begin{array}{l}\text { Non-faradaic process, i.e. } \\
\text { electrostatic }\end{array}$ & Carbonaceous materials & $\begin{array}{l}\text { Good rate capability } \\
\text { High cyclic life }\end{array}$ & $\begin{array}{l}\text { Low energy density } \\
\text { Low capacitance }\end{array}$ \\
\hline Pseudocapacitors & $\begin{array}{l}\text { Redox reactions (faradaic } \\
\text { process) }\end{array}$ & $\begin{array}{l}\text { Metal oxides } \\
\text { Conducting polymers }\end{array}$ & Low rate capability & $\begin{array}{l}\text { High energy density } \\
\text { High specific capacitance } \\
\text { High power density }\end{array}$ \\
\hline Hybrid capacitors & $\begin{array}{l}\text { Faradaic and non-faradaic } \\
\text { processes }\end{array}$ & $\begin{array}{l}\text { Combination of carbon and } \\
\text { metal oxide/conducting } \\
\text { polymer }\end{array}$ & $\begin{array}{l}\text { Polymer/carbon composite } \\
\text { has a moderate coast \& } \\
\text { stability }\end{array}$ & $\begin{array}{l}\text { High energy density } \\
\text { High power density }\end{array}$ \\
\hline
\end{tabular}

materials and the electrolytes at the boundary. The EDLCs can indeed be simplified with the following formulation as parallel plate capacitors: ${ }^{22}$

$$
C=\frac{\varepsilon_{\mathrm{o}} \varepsilon_{\mathrm{r}}}{d} A
$$

Here, $\varepsilon_{\mathrm{r}}$ represents the "dielectric constant" of the electrolyte, $\varepsilon_{\mathrm{o}}$ refers to the permittivity of vacuum, ' $d$ ' represents the Debye length and ' $A$ ' shows an active surface area that is in connection with the electrolyte. This formula shows that capacitance is affected by the active surface area. Therefore, materials based on carbon, which has a high specific surface area, high electrical conductivity, chemical stability, lower price, etc., are generally used for EDLCs. However, the limitations of carbonaceous materials, such as limited specific capacitance and low energy densities, restrict their commercialization on a large scale. ${ }^{1}$ Conway initially studied pseudo-capacity in the 1960 s, and the PCs generally depend on the strong, reversible faradic and redox reactions at the surface. ${ }^{4}$ Table 1 shows a comparison of supercapacitor types, electrode materials, and performance parameters.

\subsection{Electrochemical parameters}

In assessing the deliverable efficiency of a supercapacitor for real-life applications, determining its energy and power densities is crucial. Cyclic voltammetry (CV) and charge-discharge (CD) techniques can determine both energy and power densities, which can be determined from the equations shown below $: 8,23-27$
The specific capacitance $\left(C, \mathrm{~F} \mathrm{~g}^{-1}\right)$ of the device can be calculated using cyclic voltammetry:

$$
C_{\mathrm{CV}}=\left(\int I \mathrm{~d} V\right) / m \nu \Delta V
$$

Here, $\int I \mathrm{~d} V$ is the integral area of the CV curves $(A-V), m$ is the mass of the active material on the electrode $(\mathrm{g}), \nu$ is the scan rate and the $V$ is the voltage window.

The charge-discharge (CD) curves can also be used to evaluate the specific capacitance by the following equation.

$$
C_{\mathrm{CD}}=\frac{I \Delta t}{m(V-I R)}
$$

where $I / m, \Delta t, V$, and $I R$ are the current density, discharge time, voltage window, and voltage drop during discharge, respectively.

The specific energy density (watt-hours per kilogram) stored within a supercapacitor is

$$
E=\frac{1}{2} C_{\mathrm{s}}\left(\Delta V^{2}\right)
$$

Here, $E$ refers to the energy density and $V$ represents the voltage, which is influenced through the electroactive materials and electrolyte stability.

The specific power density (watt per kilogram) defines how quickly a device can deliver energy under a content current density to external loads. The maximum specific power density is calculated as

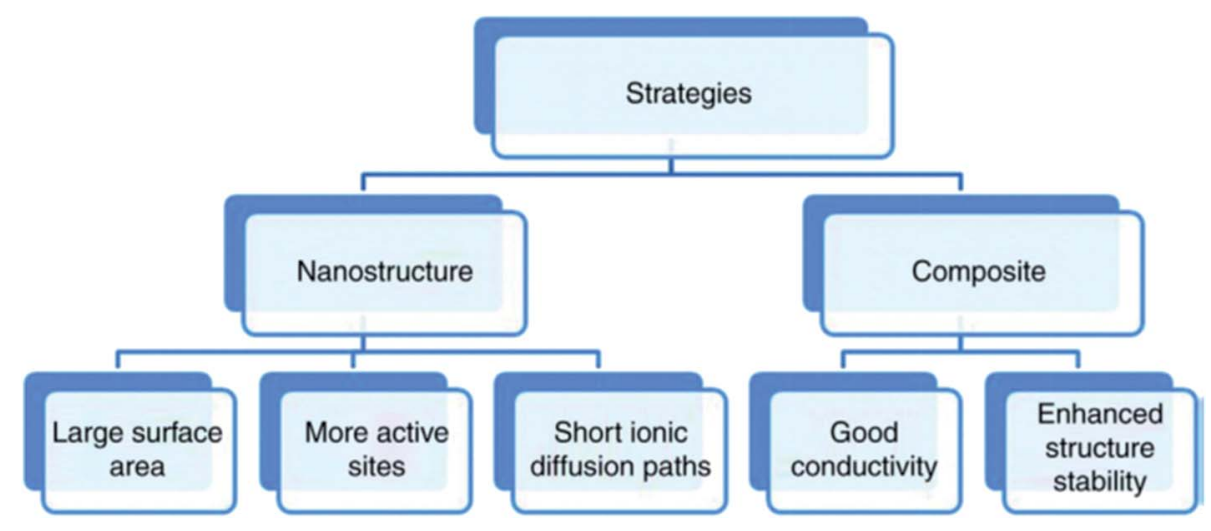

Fig. 3 Strategies adopted for the improvement of electrode performance. 


$$
P_{\max }=\frac{V^{2}}{4 R m}
$$

Here, $P_{\max }$ is the maximum power of the supercapacitor, $m$ represents the total mass of the supercapacitor, and $R$ represents the resistance of the equivalent series (in ohms).

EIS can also be used to measure and compute the ESR. Moreover, further insight into other electrical characteristics is provided by EIS. This approach provides supercapacitors with an alternating current (AC) with a small magnitude over a frequency range of $0.01 \mathrm{~Hz}$ to $1 \mathrm{MHz}$. The response is displayed in a Nyquist plot, which plots the imaginary resistance $\left(Z^{\prime \prime}\right)$ against the real resistance $(Z)$. The intersection of the impedance curve at the $x$-axis corresponds to the ESR from the Nyquist map. At low frequencies, the impedance response of a supercapacitor deviates from the ideal capacitor. This deviation is caused by the equivalent distributed resistance (EDR), which accounts for the ionic resistance of the electrolyte within the pores of the electrodes. ${ }^{28}$ Hence, increasing the number of pores in an active electrode will induce an elevated EDR.

\subsection{Electrode materials for supercapacitors}

The electrochemical presentation of a supercapacitor can also be affected by the electrode material used. The ideal electrode material blends mechanical strength and high electrochemical performance; however, most materials excel in only one of these respects. Herein, both storage mechanisms share common qualifications and strategies for selecting appropriate materials in electrodes, as demonstrated in Fig. 3.

As mentioned above, the capacitance and charge storage of a supercapacitor rely closely on the materials that are utilized for the electrodes. Therefore, an extremely effective method to address problems is to create new materials with greater ability and better functioning in comparison to the current electrode materials. The supercapacitor capacitance is highly dependent upon the high surface areas of the electrode materials. ${ }^{29,30}$ Because the entire surface area is not electrochemically accessible when the material comes into contact with an electrolyte, there is no linear shift in the measured capacitance of different materials when the surface area is increased. Therefore, a description of the electrochemically active surface area may be a better representation of the action of the electrode capacitance for certain useful surface areas. ${ }^{31-33}$ The pore size of the electrode material performs a crucial role within the electroactive surface area. Similarly, as per Largeot et al., the pore sizes of the electrode materials producing extreme double-layer capacitance was equally close to the electrolyte ion size (for an ionic liquid electrolyte), and both types of pores were either larger or smaller, resulting in a substantial decrease in the capacitance. $^{34}$ An enlargement in the pore sizes, however, widens the average distance between the center of the ion and the pore wall and thus decreases the capacity of materials with larger pores, as per eqn (1). The porosity associated with the production of high capacity is a significant parameter which includes both the pore size and pore size dissemination for a particular area of the material. Therefore, the capacitance relies heavily on the surface area of the electrode that is reachable to the electrolyte. Normally, electrode materials are classified into three main types: (i) transition metal oxides (ii), carbon-based materials, and (iii) conductive polymers. From the morphology point of view, numerous electrode materials, such as $\mathrm{RuO}_{2}, \mathrm{NiO}, \mathrm{MnO}_{2}, \mathrm{NiCo}_{2} \mathrm{O}_{4}$, polyaniline (PANI), polypyrrole (PPy), one-dimensional materials (nanotubes and nanowires), two-dimensional materials (nanosheets and nanodiscs), and three-dimensional materials (nanoarchitectures), have been investigated; these cannot be addressed in detail in a brief review article. Hence, a brief comparison of the most relevant constraints is presented in Table 2 .

By enhancing the capacitive double-layer charge and surface area, carbonaceous materials tend to increase the interaction between the deposited material and electrolyte. ${ }^{\mathbf{1 6}}$ Additionally, efficiency can be improved by the development of porous nanostructures, which provide added ion-adsorption and active sites for the charge transfer reactions. ${ }^{35}$

Metal-organic frameworks (MOFs), also known as porous (coordination) polymers (PCPs), are a class of compounds that consists of metal ions linked with organic linkers to form single, two, or three-dimensional structures. ${ }^{35-38}$ Importantly, MOFs are considered to be bifunctional materials with both sacrificial templates and metal precursors; thus, they can play a significant part in the development of nano, micro, or hollow structured materials with internal holes and operational shells. ${ }^{17,39}$ Due to their increased surface areas, tunable pores, adjustable structures, and prospective applications, these porous materials have attracted enormous interest. Various research groups make significant contributions to the coordinated development of MOFs on the nano and microscales. We also published several research papers focused on MOFs in Elsevier and other respected journals. ${ }^{40-58}$ Another report discusses the possibilities of using MOFs as a template to prepare functional nanostructures. ${ }^{59}$

Table 2 Overall comparison of electrode materials with different parameters

\begin{tabular}{|c|c|c|c|c|c|c|}
\hline Materials used & Surface area & Pore size distribution & $\begin{array}{l}\text { Specific } \\
\text { capacitance }\end{array}$ & Conductivity & $\begin{array}{l}\text { Rate } \\
\text { capability }\end{array}$ & Stability \\
\hline Carbon & High & $\begin{array}{l}\text { Numerous approaches } \\
\text { to tailor pore size distribution }\end{array}$ & Low & High & High & Good \\
\hline Metal oxides & Low & Difficult to tailor pore size distribution & High & Low & Low & Poor \\
\hline $\begin{array}{l}\text { Metal oxide/conducting } \\
\text { polymer-carbon composite }\end{array}$ & $\begin{array}{l}\text { Controlled } \\
\text { by a carbon } \\
\text { support }\end{array}$ & $\begin{array}{l}\text { Numerous approaches } \\
\text { to tailor pore size distribution }\end{array}$ & High & Medium to high & High & Good \\
\hline
\end{tabular}




\section{Electrode materials based on zeolitic imidazolate frameworks (ZIFs)}

Zeolitic imidazolate frame (ZIFs), a MOF class, can be synthesized with different characteristics of unique particle shapes, exceptional porosities, and surface functionality by combining organic and inorganic constituents. ${ }^{18,19}$ With selective pyrolysis through a controlled environment, as shown in Fig. 4, ZIFs can be transformed into porous carbon (PC) or metal compounds featuring special nanostructures. Parent ZIFs can also be prepared by the combination of organic and inorganic compositions via facile coordination chemistry with the management and manipulation of the surface area, pore volume and porous structure. Due to their porous structure, ZIFs are being explored as a template for the preparation of porous carbon/metal oxides, etc. The improved pores of the surface area can be used for interfacial transport and also provide small diffusion paths for the electrolyte. ${ }^{60-62}$

Compared with other carbon-based materials produced via utilizing traditional methods, templates, or precursors, ZIFderived carbons have outstanding merits of facile preparation with inherent diversity, offering accurate control of the physicochemical properties. In the last decade, the use of materials derived from ZIFs in the field of electrochemical conversion and energy storage has developed into a rapidly expanding research area. $^{37}$

\subsection{Zeolitic imidazolate framework-derived nanoporous carbon (NPC)}

The preparation of ZIF materials with required properties and morphologies strongly depends on the selection of the initiating materials (such as solvents, inorganic salts, and organic

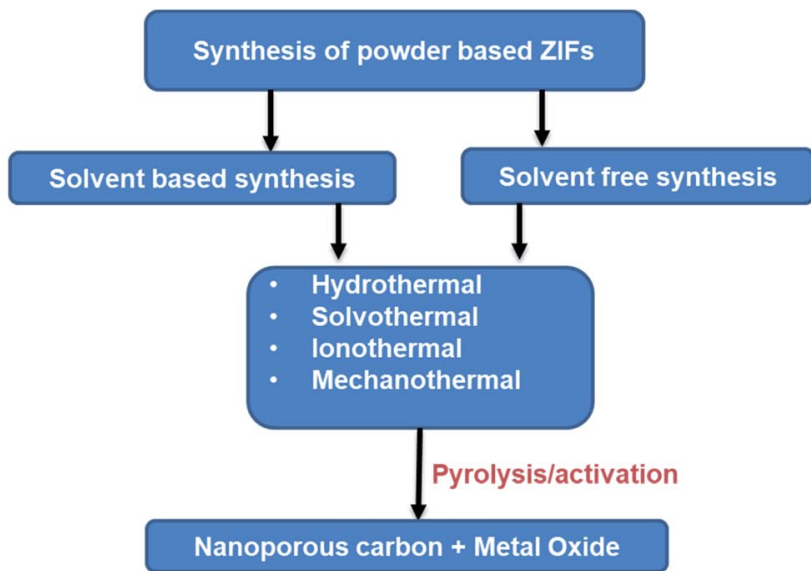

Fig. 5 Summary of the synthetic methods to convert ZIFs to ZIFderived NPC and MO materials.

ligands, and solvents) and the synthesis conditions (i.e. pH, composition, reaction temperature, and solvent concentration). ${ }^{64}$ To date, a wide range of synthetic methods have been established, including solvothermal, sonochemical, and hydrothermal processes. ${ }^{65-68}$ The general synthesis schemes for powder-based ZIFs and ZIF-derived porous carbon-based materials are shown in Fig. 5 .

In the solvothermal synthesis process, solvents such as ethanol, methanol, dialkyl formamide, and pyridine are most commonly used. Generally, the reaction takes several hours based on the precursors used. Salunkhe et al. used zinc nitrate and cobalt nitrate as the metal suppliers and methanol as the solvent to mix with 2-methylimidazolate (MeIm) for the preparation of $\mathrm{Zn} / \mathrm{Co}-\mathrm{ZIFs}{ }^{69}$

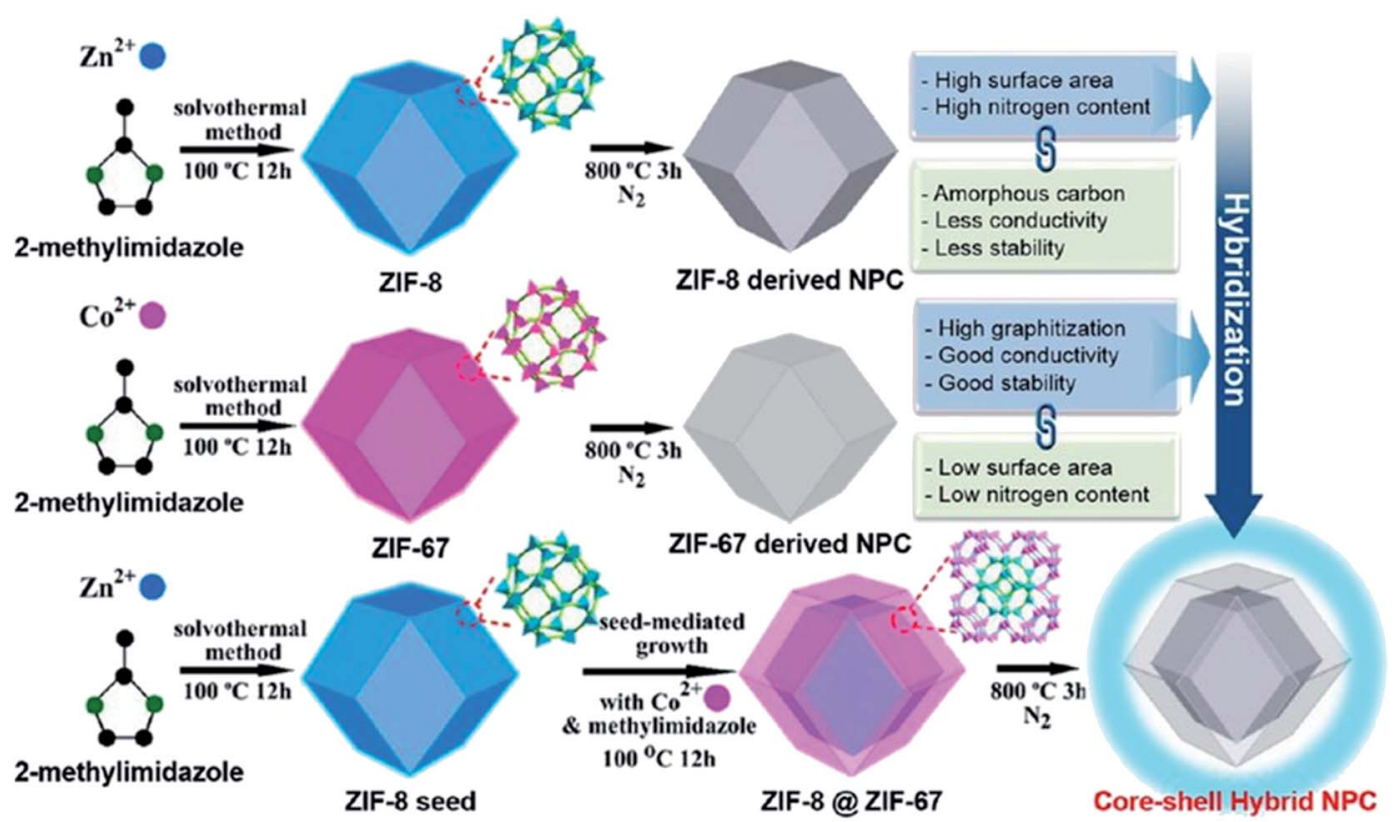

Fig. 4 Production of ZIF-8 and ZIF-67-derived nanoporous carbon and its advantages and disadvantages. Reproduced with permission from the American Chemical Society, ref. 63, Copyright 2015. 
a

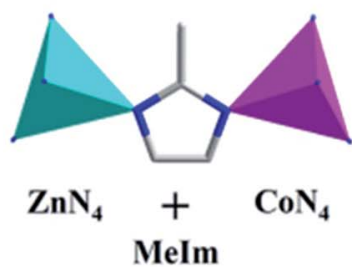

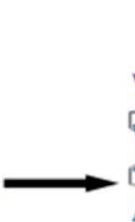

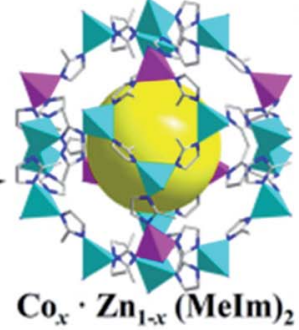

b

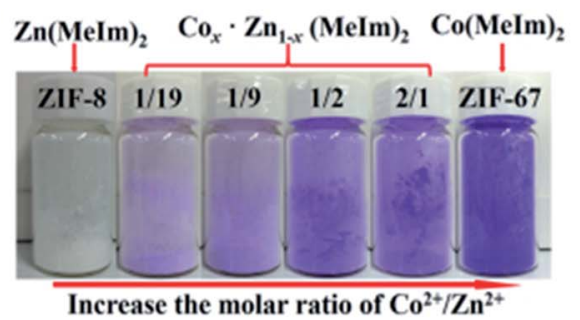

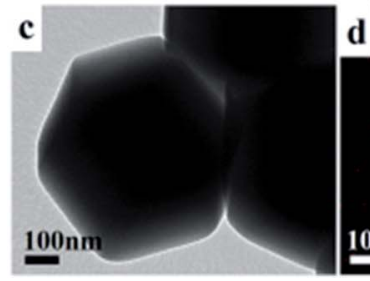
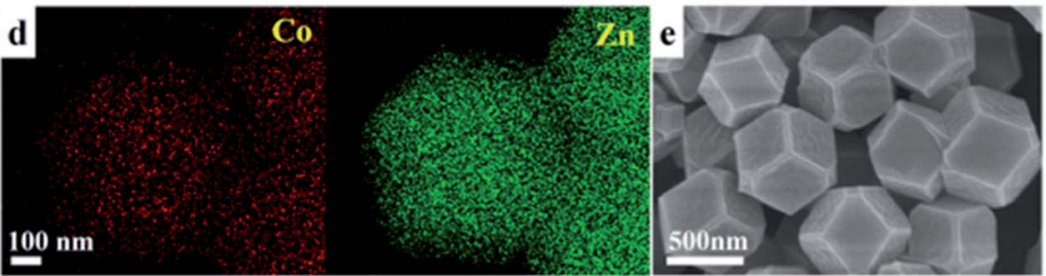

Fig. 6 (a) Preparation of Zn/Co-ZIFs and (b) colors of Zn/Co-ZIFs with various compositions; (c) TEM image, (d) elemental mapping and (e) SEM image of Zn/Co-ZIFs. Reproduced with permission from ref. 72, Copyright 2016, Nature Publishing Group.

Cobalt nitrate hexahydrate and 2-methyl imidazole solutions were mixed and stirred to obtain ZIF-67 (Co) under ambient conditions, after which the resulting precipitates were washed and then vacuum-dried. In the strong reduction atmosphere $\left(\mathrm{Ar} / \mathrm{H}_{2}\right)$, the obtained ZIF-67 can be further transformed into carbon nanotubes by a controlled two-step annealing cycle. ${ }^{70}$ Recently, the hydrothermal method for synthesizing ZIFs has become highly preferred, wherein water as a solvent has been utilized for the facile formation of various types of ZIFs. ZIFs can be used with different metals for the facile formation of organic-inorganic ZIF networks. By changing the reaction conditions, temperature, and time, different ZIF coordination structures can be formulated. ${ }^{71}$ Fig. 6 a displays the proposed crystal structure for bimetallic ZIFs. Upon changing the cobalt ratio in the formulation, the color of the ZIF powders changed from white to purple, lavender, and ultimately purple (Fig. 6b).
These results indicate that the bimetallic ZIF possesses a polyhedron morphology (Fig. 6c). ${ }^{69}$ The same method was used to prepare $\mathrm{Zn}$-Co-ZIF as the precursor of porous $\mathrm{ZnCo}_{2} \mathrm{O}_{4}$ (Fig. 7). Huang and his coworkers synthesized porous hollow $\mathrm{Co}_{3} \mathrm{O}_{4}$ with rhombic dodecahedral nanostructures from a well-known MOF compound, i.e. ZIF-67, using the precursor by a solvothermal process followed by two-step calcination. ${ }^{73}$

Sol-gel is a simple technique to synthesize materials with superior concentration and uniformity. This technique is called the sol-gel method because the micro-particles in the solution agglomerate under standardized conditions to form an interconnected grid (gel). There are two different versions of the solgel method based on the kind of precursor utilized, i.e. the colloidal method and polymeric or alkoxide method.

Liu et $a l .{ }^{74}$ demonstrated that the sol-gel deposition of $\mathrm{NiCo}_{2} \mathrm{O}_{4}$ thin films showed a better specific capacitance of 2157

(a)

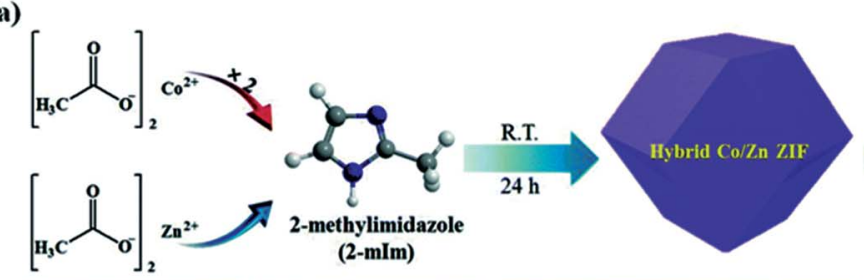

(b)

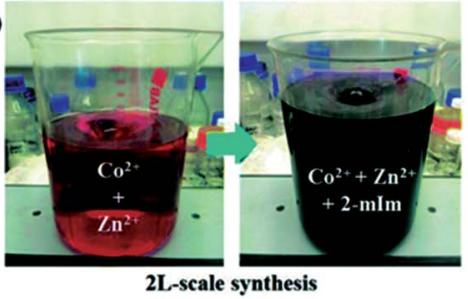

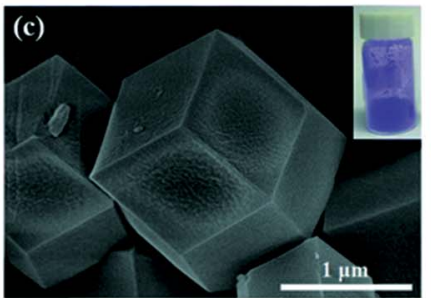
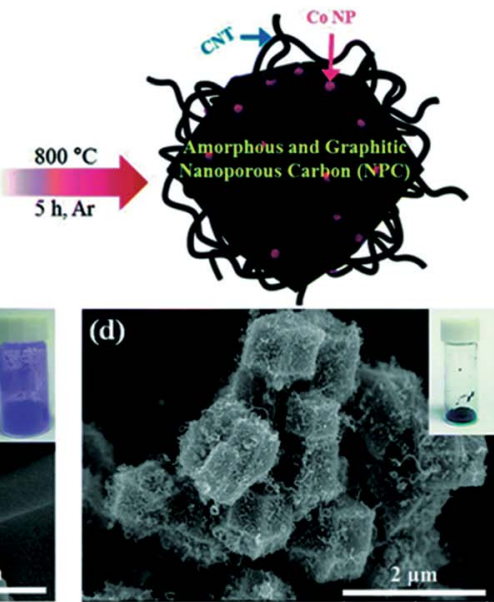

Fig. 7 Synthesis of a Co/Zn hybrid MOF and nano-porous carbon. (a) Preparation of Co/Zn (2 : 1) hybrid-ZIF from a metal precursor and 2methylimidazole organic linker followed by carbonization to produce graphitic and amorphous nanoporous carbons. (b) Pictures of $2 \mathrm{~L}$-scale production. SEM images of (c) a bimetallic Co/Zn hybrid ZIF and (d) carbonized nano-porous carbon. Reproduced with permission from the Royal Society of Chemistry ref. 78, copyright 2016. 


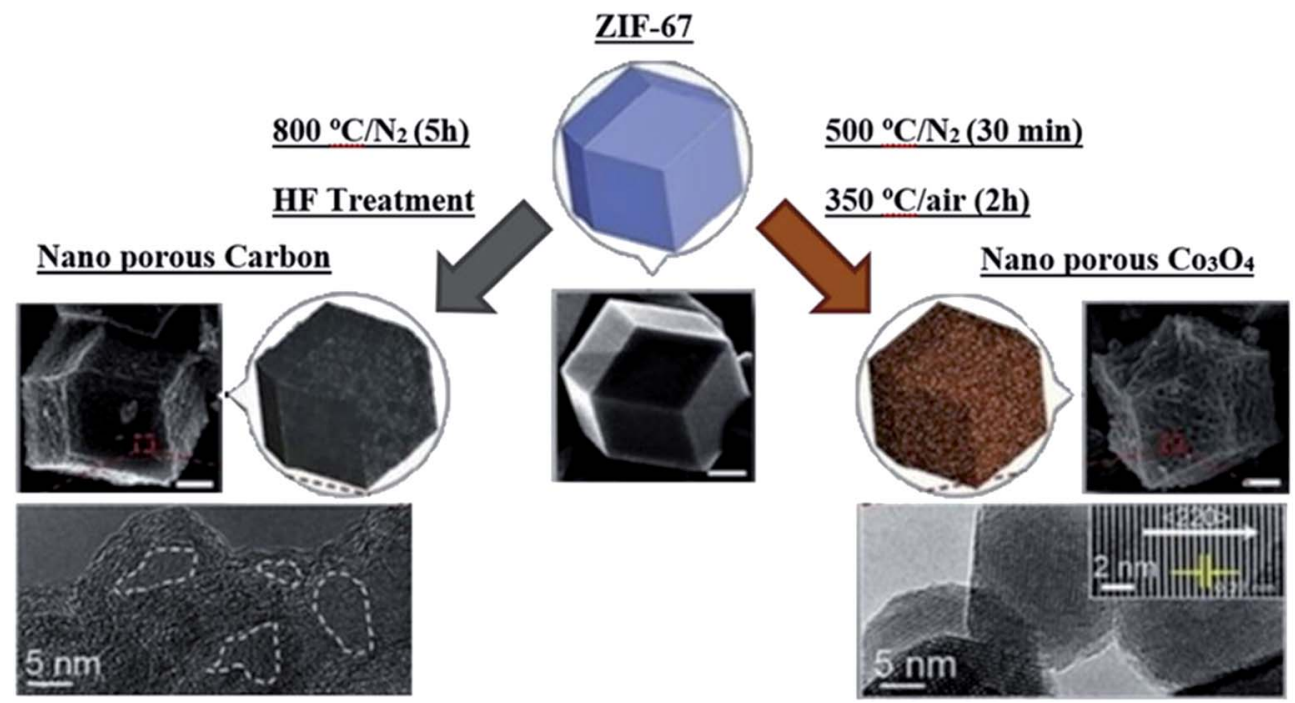

Fig. 8 Representation of the preparation of nanoporous carbons and nano-porous $\mathrm{CO}_{3} \mathrm{O}_{4}$ from $\mathrm{ZIF}-67$ as a precursor, which shows the retention of the morphology of the parent ZIF-67, as shown in the SEM and TEM images. Reproduced with permission from American Chemical Society, ref. 35, Copyright 2015.

$\mathrm{F} \mathrm{g}^{-1}$ at a current density of $0.133 \mathrm{~mA} \mathrm{~cm}{ }^{-2}$ and good cyclic stability of $96.5 \%$ capacity retention over 10000 cycles. Fig. 8 shows the synthesis schematic of a hybrid ZIF from a metal precursor and organic linker, thus producing porous carbon.

Moreover, carbon and hybrid materials based on metals can be fabricated using MOF-based templates. The benefits of this preparation method include: (1) the wide variety of MOF materials with various metal ion compositions offer diverse selections for target materials; (2) in high-temperature carbonization, the harmonization of metal ions with organic ligands in MOFs can efficiently avert the accumulation of metal oxidebased nanoparticles and damage of the nanostructures; (3) loading positions for the incorporation of active materials can be provided by the highly porous structures of MOFs; (4) the synthesis procedures are simple, and the synthesis conditions are generally mild; and (5) the as-obtained materials are

Table 3 Summary of the performance of ZIF-derived porous carbon electrodes in supercapacitors

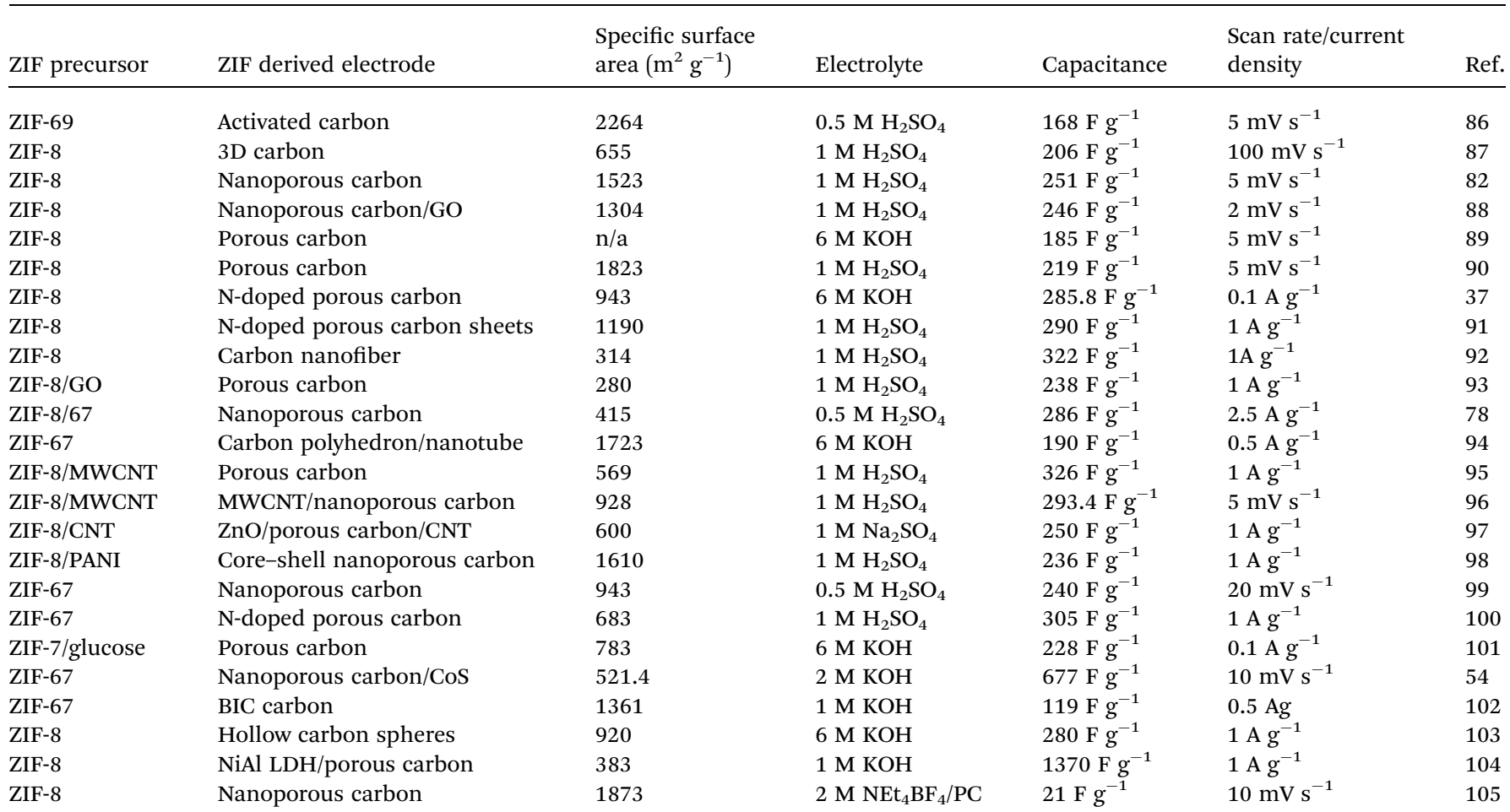


characterized by diverse morphologies, such as nanorods, nanowires, nano-cubes, hollow polyhedrons, and hollow spheres. For example, 2-methylimidazoles of ZIF-67 can be fabricated to a composite of N-doped PC and Co nanoparticles by simple pyrolysis under an inert environment, leading to $\mathrm{Co} /$ $\mathrm{N}$-doped PC nanocomposites with high dispersion. ${ }^{75} \mathrm{~A}$ facile ZIF-induced strategy was proposed by An and co-workers to synthesize core-shell structured PC decorated with $\mathrm{Co} / \mathrm{Co}_{3} \mathrm{O}_{4}$ nanoparticles. ${ }^{76}$ Core-shell CNT@NiO hybrids were synthesized via a wet chemical method accompanied by high-temperature treatment, while porous carbon polyhedrons were prepared by the direct calcination of Zn-based MOFs. An asymmetric supercapacitor based on CNT@NiO//porous carbon polyhedrons showed very good performance for energy storage, such as extraordinary power density, large energy density, and robust cycling stability. ${ }^{77}$

\subsection{Nanocomposites of ZIF-derived nanoporous carbon and metal oxides}

Because of the existence of a basic surface area of the ZIFderived porous carbon and transition metal oxides, ZIFs have been one of the most promising architectures and precursors for the preparation of carbons with a high surface area for energy storage, $\mathrm{CO}_{2}$ uptake, hydrogen adsorption, and electrocatalysis with the presence of rich carbon and nitrogen species. ${ }^{37,79,80}$ The structure of ZIF-derived carbon can be modified via carbonization and activation processes. When this activation of nanostructures is completed, then diffusion of ions occurs over the pores of their nanostructures. As this activation of nanostructures is achieved, through the pores of their nanostructures, ion diffusion occurs. This free ion diffusion is a major factor in the electrodes' effective electrochemical function. ${ }^{\mathbf{8 1 , 8 2}}$

Yamauchi et $a .^{83}$ demonstrated the development of an asymmetric supercapacitor that has both nano-porous carbon and nano-porous cobalt oxides $\left(\mathrm{Co}_{3} \mathrm{O}_{4}\right)$ from ZIF-67. When this precursor was heated under nitrogen gas, it formed nanoporous carbons; however, when it was heated in the presence of air, it caused the organic species to decompose, which further resulted in nanoporous $\mathrm{Co}_{3} \mathrm{O}_{4}$. The original morphology (polyhedral) of the parent MOF, i.e. ZIF-67, was retained in both of the above cases (Fig. 8).

Many nano-pores were detected on the surface of the nanoporous carbons. Nano-porous $\mathrm{Co}_{3} \mathrm{O}_{4}$, on the other hand, was composed of arbitrarily accumulated granulated nanocrystals with an average size of $15-20 \mathrm{~nm}$. The measurements of the surface area of the as-prepared nano-porous carbons and the nano-porous $\mathrm{Co}_{3} \mathrm{O}_{4}$ were respectively 350 and $148 \mathrm{~m}^{2} \mathrm{~g}^{-1}$. The asymmetric supercapacitor formed by the combination of the above two electrodes $\left(\mathrm{Co}_{3} \mathrm{O}_{4} / /\right.$ carbon $)$ represented very high specific energy and specific power of approximately $36 \mathrm{~W} \mathrm{~h} \mathrm{~kg}^{-1}$ and $8000 \mathrm{~W} \mathrm{~kg}^{-1}$ in comparison to the symmetric supercapacitors (carbon//carbon $\left(\sim 7 \mathrm{~W} \mathrm{~h} \mathrm{~kg}{ }^{-1}\right)$ and $\mathrm{Co}_{3} \mathrm{O}_{4} / / \mathrm{Co}_{3} \mathrm{O}_{4}$ $\left.\left(\sim 8 \mathrm{~W} \mathrm{~h} \mathrm{~kg}^{-1}\right)\right)$.

Zhang et al. reported an initial example of $\mathrm{Co}_{3} \mathrm{O}_{4}$ nanostructures which were obtained from Co(II) MOF precursors. ${ }^{\mathbf{8 4}}$
He prepared a Co(II) MOF with a $p$-benzene dicarboxylic acid (BDC) ligand using the solvothermal technique. Characterization of the MOF was performed by FTIR and TGA/DSC. The authors suggested the formula as $\left[\mathrm{Co} \cdot(\mathrm{BDC})_{2}\right]_{n}$. At $450{ }^{\circ} \mathrm{C}$, solidstate heat treatment of the Co(II) MOF was performed, forming porous nano-/micro superstructures of $\mathrm{Co}_{3} \mathrm{O}_{4}$. The nanostructure thus formed was characterized via XRD and SEM diffraction techniques. The specific capacitance of $208 \mathrm{~F} \mathrm{~g}^{-1}$ at a current density of $1 \mathrm{~A} \mathrm{~g}^{-1}$ and retention capacity of 97 percent with 1000 charge/discharge cycles in 6.0 M aqueous $\mathrm{KOH}$ solution as an electrolyte was demonstrated by electrochemical characterization of prepared porous $\mathrm{Co}_{3} \mathrm{O}_{4}$ superstructures, demonstrating their supercapacitor property.

Wang et $a l .{ }^{85}$ fabricated an asymmetric supercapacitor using one 2D MOF precursor. A 2D sheet-like Co-MOF was prepared via the reaction of $\mathrm{Co}^{2+}$ and 2-methylimidazole in $\mathrm{H}_{2} \mathrm{O}$, and it was developed on the surface of carbon (CC@Co-MOF). Its 2D layered crystal structure was confirmed by Pawley's refinement of the PXRD data. The as-prepared 2D cobalt-based ZIF precursor was further converted to $\mathrm{Co}_{3} \mathrm{O}_{4}$ nanosheets (CC@ $\mathrm{Co}_{3} \mathrm{O}_{4}$ ) or $\mathrm{CC} @ N C$ through the process of thermolysis. Lastly, using $\mathrm{CC} @ \mathrm{Co}_{3} \mathrm{O}_{4}$ as a cathode and $\mathrm{CC} @ \mathrm{NC}$ as an anode with a poly(vinyl alcohol) $\mathrm{KOH}$ gel as the electrolyte, a flexible, asymmetric supercapacitor was developed. In comparison to the MOF-based supercapacitors, it is evident from the Ragone plot that the $\mathrm{CC} @ \mathrm{Co}_{3} \mathrm{O}_{4} / \mathrm{CC} @ N C$ system showed exceptional electrochemical efficiency, reflecting the significance of this extraordinary asymmetric supercapacitor. Table 3 summarizes the specific capacitance reported for porous carbon electrodes derived from ZIFs at different scan rates or current densities in supercapacitors.

\subsection{ZIF-derived metal oxide/sulfide-based electrodes}

Generally, a highly porous architecture promotes the transport of electrolyte ions and thus improves the supercapacitor behavior of the electrode; the electrical conductivity also contributes significantly to increasing the capacitance. ${ }^{\mathbf{1 0 6}}$ One promising approach is the growth or mixing of MOF-derived metal compounds on or with highly conductive substrates or additives, such as nickel foam (NF), CNTs, graphene, activated carbon, carbon aerogel, and $\mathrm{MoS}_{2} \cdot{ }^{\mathbf{1 0 7 - 1 1 1}}$ Not only the electrical conductivity but also the number of active sites on the surface of the electrode can be improved by tuning the linkage compound amongst the active material and the conductive substrate/ additive. ${ }^{112}$ Compared with nickel oxides, nickel sulfides often have better structural stability and faster electron transfer, which is ascribed to the lesser electronegativity value of sulfur in comparison to oxygen. ${ }^{113,114}$ The replacement of $\mathrm{O}^{2-}$ by $\mathrm{S}^{2-}$ in MOF-derived Ni oxides can effectively improve its conductivity and electrochemical activity.

Ahmad and her co-workers demonstrated a framework of $\mathrm{N}$ doped carbon nanotubes (N-CNTs) from a single precursor of ZIF-67 (Fig. 9). The ZIF-67 precursor not only functions as the template to form the hollow framework but also serves as the source of $\mathrm{C}$ and $\mathrm{N}$ to aid the growth of CNTs by the catalysis of in situ formed metallic Co nanoparticles. The derived materials 

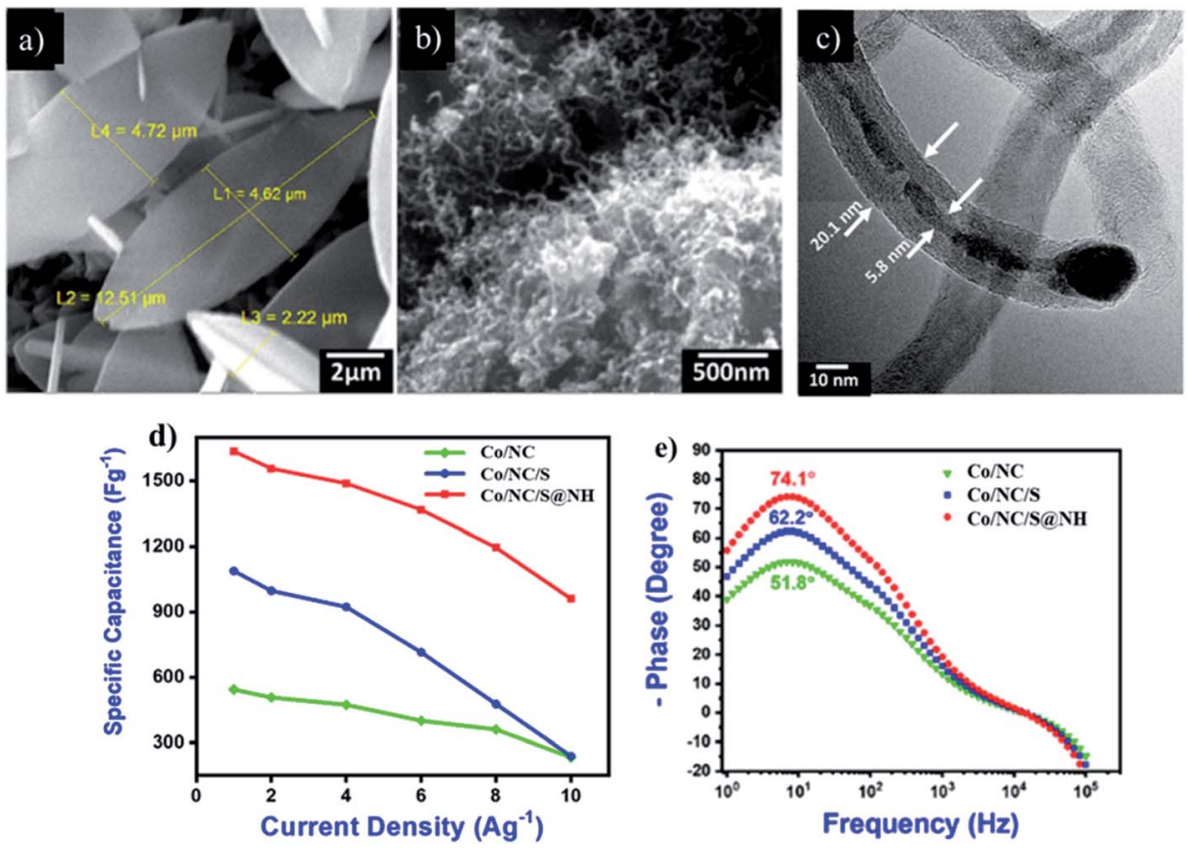

Fig. 9 SEM images of before (a) and after ( $b$ and $c$ ) the synthesis of ZIF-67 derived $n$-doped CNTs decorated with sulfur and nickel hydroxide, (d) specific capacitance calculated from CV curves as a function of scan rate for the Co/NC, Co/NC/S, and Co/NC/SaNH electrodes, (e) Bode phase angle plots of synthesized electrodes on Ni foam. Reproduced with permission from Elsevier, ref. 40, and Copyright 2020.

exhibit excellent performance for high-performance supercapacitors. The Co/NC/S@NH hierarchical hybrid electrode displayed enhanced capacitance of $1636 \mathrm{~F} \mathrm{~g}^{-1}$ at $1 \mathrm{~A} \mathrm{~g}^{-1}(982 \mathrm{C}$ $\mathrm{g}^{-1}$ or $273 \mathrm{~mA} \mathrm{~h}^{-1}$ ) with exceptional cyclic stability. The $\mathrm{Co} / \mathrm{NC} /$ S@NH exhibited capacity retention of $94 \%$ over 5000 cycles. ${ }^{40}$

Chen et al. ${ }^{115}$ synthesized self-supported $\mathrm{Ni}_{3} \mathrm{~S}_{2}$ nanosheet arrays by the thermal decomposition of a MOFs precursor followed by sulfidation. The as-obtained $\mathrm{Ni}_{3} \mathrm{~S}_{2}$ nanosheet arrays exhibited outstanding supercapacitance properties, delivering capacitance of $1000 \mathrm{~F} \mathrm{~g}^{-1}$ at a very high current density of $50 \mathrm{~A} \mathrm{~g}^{-1}$ for enormous cycles of charge-discharge, i.e. 20000 cycles. The unique nanosheet structure of $\mathrm{Ni}_{3} \mathrm{~S}_{2}$ contributed to the outstanding electrochemical behavior because it significantly facilitated the surface faradaic redox reaction. Also, NiS has received particular interest as a favorable material for electrodes due to its high theoretical specific capacitance. Lou et al. ${ }^{116}$ synthesized cubic frame-like NiS hollow nanoparticles via the calcination of MOFs precursors coupled with an anion exchange method. The NiS nanoframe $(300 \mathrm{~nm})$ displayed a superb specific capacitance of $2112 \mathrm{~F} \mathrm{~g}^{-1}$ at a current density of $1 \mathrm{~A} \mathrm{~g}^{-1}$. Liu et al. ${ }^{117}$ introduced $\mathrm{S}^{2-}$ ions into ZIF-derived $\mathrm{NiCO}_{2} \mathrm{O}_{4}$ to enhance its intrinsic conductivity and

Table 4 Summary of the performance of ZIF-derived metal oxide/sulfide and hydroxide-based electrodes in supercapacitors

\begin{tabular}{|c|c|c|c|c|c|c|}
\hline ZIF precursor & ZIF derived electrode & Specific surface area $\left(\mathrm{m}^{2} \mathrm{~g}^{-1}\right)$ & Electrolyte & Capacitance & Current density & Ref. \\
\hline \multicolumn{7}{|c|}{ ZIF-derived metal oxides/sulfides and hydroxides based electrodes } \\
\hline ZIF-67 & $\mathrm{Co}_{3} \mathrm{O}_{4}$ & $\mathrm{n} / \mathrm{a}$ & $1 \mathrm{M} \mathrm{KOH}$ & $706 \mathrm{~F} \mathrm{~g}^{-1}$ & $1 \mathrm{Ag}^{-1}$ & 122 \\
\hline ZIF-67 & $\mathrm{Co}_{3} \mathrm{O}_{4} / \mathrm{MoS}_{2}$ & 257 & $2 \mathrm{M} \mathrm{KOH}$ & $1076 \mathrm{~F} \mathrm{~g}^{-1}$ & $1 \mathrm{Ag}^{-1}$ & 123 \\
\hline ZIF-67 & $\mathrm{Co}(\mathrm{OH})_{2}$ & 630 & $6 \mathrm{M} \mathrm{KOH}$ & $1263 \mathrm{~F} \mathrm{~g}^{-1}$ & $1 \mathrm{Ag}^{-1}$ & 124 \\
\hline ZIF-67 & $\mathrm{Co}(\mathrm{OH})_{2} /$ nanocages/graphene & $\mathrm{n} / \mathrm{a}$ & $1 \mathrm{M} \mathrm{KOH}$ & $1205 \mathrm{~F} \mathrm{~g}^{-1}$ & $1 \mathrm{~A} \mathrm{~g}^{-1}$ & 125 \\
\hline ZIF-67 & $\mathrm{CoS}$ & 110 & $2 \mathrm{M} \mathrm{KOH}$ & $980 \mathrm{~F} \mathrm{~g}^{-1}$ & $1 \mathrm{~A} \mathrm{~g}^{-1}$ & 119 \\
\hline Co-ZIF & $\mathrm{Co}_{9} \mathrm{~S}_{8}-\mathrm{NSA} / \mathrm{NF}$ & $\mathrm{n} / \mathrm{a}$ & $1 \mathrm{M} \mathrm{KOH}$ & $1098.8 \mathrm{~F} \mathrm{~g}^{-1}$ & $0.5 \mathrm{Ag} \mathrm{g}^{-1}$ & 120 \\
\hline ZIF-67 & $\mathrm{NiCo}_{2} \mathrm{O}_{4} / \mathrm{Co}_{3} \mathrm{O}_{4}$ & 33.6 & $6 \mathrm{M} \mathrm{KOH}$ & $1046 \mathrm{~F} \mathrm{~g}^{-1}$ & $1 \mathrm{Ag} \mathrm{g}^{-1}$ & 128 \\
\hline ZIF-8 & $\mathrm{ZnO} / \mathrm{C} / \mathrm{NiCo}_{2} \mathrm{O}_{4}$ & $\mathrm{n} / \mathrm{a}$ & $2 \mathrm{M} \mathrm{KOH}$ & $2650 \mathrm{~F} \mathrm{~g}^{-1}$ & $5 \mathrm{~A} \mathrm{~g}^{-1}$ & 129 \\
\hline ZIF-67 & $\mathrm{NiCO}_{2} \mathrm{O}_{4}$ & 43.2 & $6 \mathrm{M} \mathrm{KOH}$ & $956 \mathrm{~F} \mathrm{~g}^{-1}$ & $1 \mathrm{~A} \mathrm{~g}^{-1}$ & 117 \\
\hline $\mathrm{Mn} / \mathrm{Co}-\mathrm{ZIF}$ & $\mathrm{MnCo}_{2} \mathrm{O}_{4}$ & 117 & $2 \mathrm{M} \mathrm{KOH}$ & $1763 \mathrm{~F} \mathrm{~g}^{-1}$ & $1 \mathrm{~A} \mathrm{~g}^{-1}$ & 130 \\
\hline
\end{tabular}


supercapacitance performance. Increases in both the sizes of the pores and the surface area were observed after the introduction of $\mathrm{S}^{2-}$. Compared to $\mathrm{O}^{2-}, \mathrm{S}^{2-}$ ion possesses a larger anion size, which could lead to a larger strain inside the crystalline structure to create defects. Thus, the structural change induced by the incorporation of $\mathrm{S}^{2-}$ allows the liquid electrolyte to more easily access the inner space of the porous materials. ${ }^{118}$

Table 4 lists the performance of selected MOF-derived metal oxide and metal sulfide-based compounds as active electrodes of supercapacitors. Lou et al. ${ }^{\mathbf{1 1 9}}$ prepared CoS nanoboxes with a double-shelled hollow structure via a "hard template method" utilizing ZIF-67 nanocubes as a precursor and a subsequent sulfidation procedure. The synthesized CoS nanoboxes had unique morphology features of excellent robustness, suitable mesopores, and high specific surface area, and they showed excellent cycling performance, fast transportation of ions, and rich redox reactions. Using leaf-like ZIF as the precursor and subsequent sulfidation, porous cobalt sulfide nanosheets were successfully prepared, showing outstanding capacitance of 1010 $\mathrm{F} \mathrm{g}^{-1}$ without the use of any binder. ${ }^{120}$ ZIF-67-derived $\mathrm{Co}_{9} \mathrm{~S}_{8}$ hollow nanoparticles were also applied as high-performance electrodes in supercapacitors. ${ }^{\mathbf{1 2 1}}$

\subsection{Cobalt-based ZIF-derived metal oxide and hydroxide electrodes}

Among various metal compounds, cobalt oxide $\left(\mathrm{Co}_{3} \mathrm{O}_{4}\right)$ is regarded as an outstanding electrode for applications related to supercapacitors due to its relatively low cost, environmentally friendly nature, and great electrochemical activity and stability (e.g., high theoretical capacitance of $\sim 3600 \mathrm{~F} \mathrm{~g}^{-1}$ ). ${ }^{133}$ Another Co-based material that has gained research interest for application in supercapacitor electrodes is cobalt hydroxide. $\mathrm{Co}(\mathrm{OH})_{2}$ possesses a layered structure with a large inter-layer space and high surface area; it can also be prepared through the thermolysis of MOF precursors. The MOF-derived $\mathrm{Co}(\mathrm{OH})_{2}$ maintains its unique porous structure, which is valuable for rapid ion transportation, rich redox reactions and robust structure stability of supercapacitor electrodes. ${ }^{\mathbf{1 2 4}}$

Nanoporous MOF-derived $\mathrm{Co}_{3} \mathrm{O}_{4}$ electrodes have been developed for application in asymmetric supercapacitors. ${ }^{83}$ Of significance, the polyhedral shape of the MOF precursor (e.g., ZIF-67) could be well preserved by $\mathrm{Co}_{3} \mathrm{O}_{4}$ by fine-tuning the synthesis procedures. ${ }^{134}$ The nanoporous structures led to higher current sweeps and contributed greatly to the high performance of supercapacitors. Another double-walled tetrahedral MOF was also chosen as a precursor to formulate porous hollow $\mathrm{Co}_{3} \mathrm{O}_{4}$, which showed potential as a supercapacitor electrode with better performance because of its hollow structure and high electronic conductivity. ${ }^{135}$ Fig. 10 presents a ceriabased composite of a MOF and GO that shows excellent performance compared to a CNTs-based composite.

\subsection{ZIF-derived layered double hydroxide electrodes}

Layered-double-hydroxides (LDHs) composed of Fe, Ni, Co, or NiCo are attracting wide attention as active electrodes of supercapacitors due to their distinct characteristics, such as anion exchange, intercalation, high theoretical capacity and specific surface area. ${ }^{137-139}$ However, concerns exist about accumulation and lower electrical conductivity because of hydrogen bonding as well as the nano-size effect, which lead to reduced performance. A hollow micro or nanostructure with clear inner spaces and functional shells may efficiently avoid accumulation of the LDH materials. On the other hand, porous structures may assist the infiltration of the electrolytes, aid the
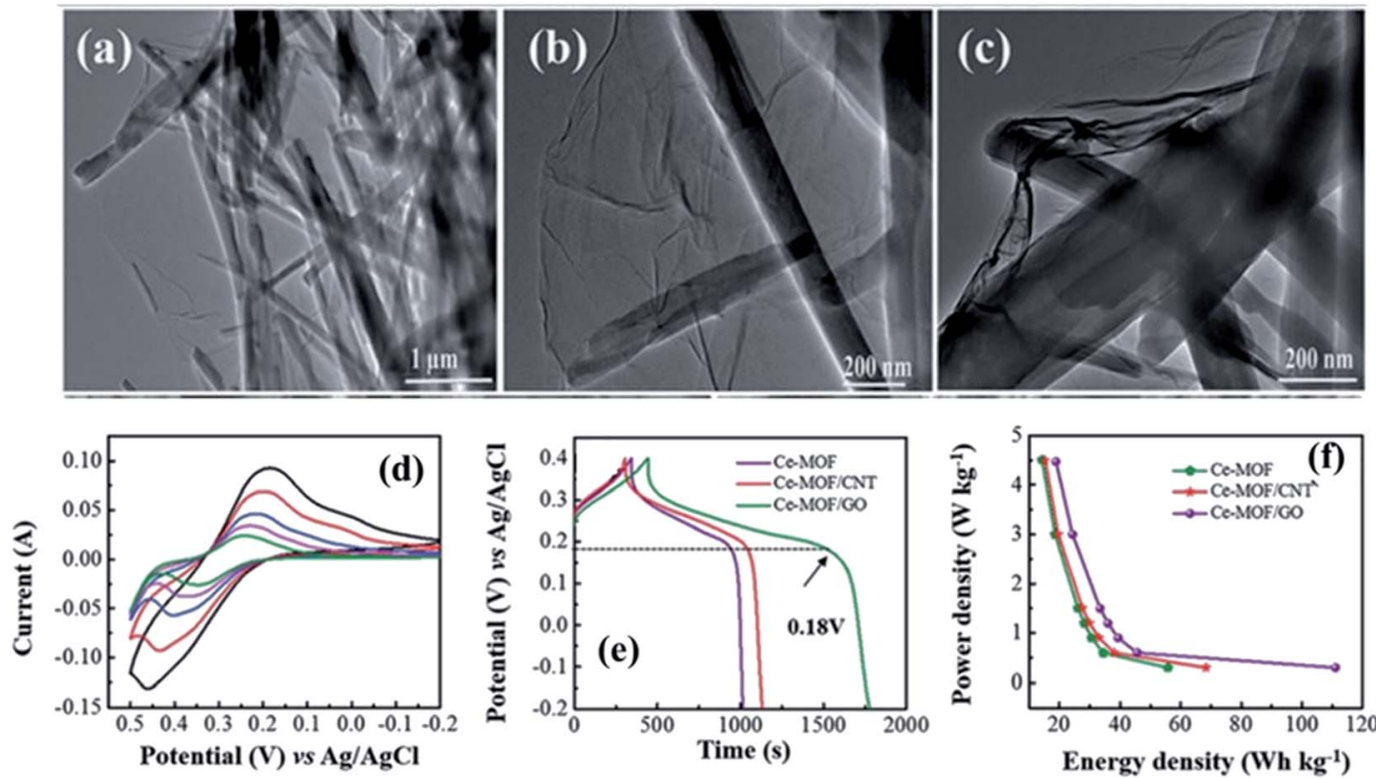

Fig. 10 TEM images of $(a-c) C e-M O F / G O$, (d) cyclic voltammetry response of the Ce-MOF/GO composite at various scan rates in $3 \mathrm{M}$ KOH electrolyte, (e) galvanostatic charge-discharge behavior in $3 \mathrm{M} \mathrm{KOH}$ electrolyte, and (f) Ragone plots of the Ce-based composites. Reproduced with the approval from ref. 136, Copyright 2018, the Royal Society of Chemistry. 

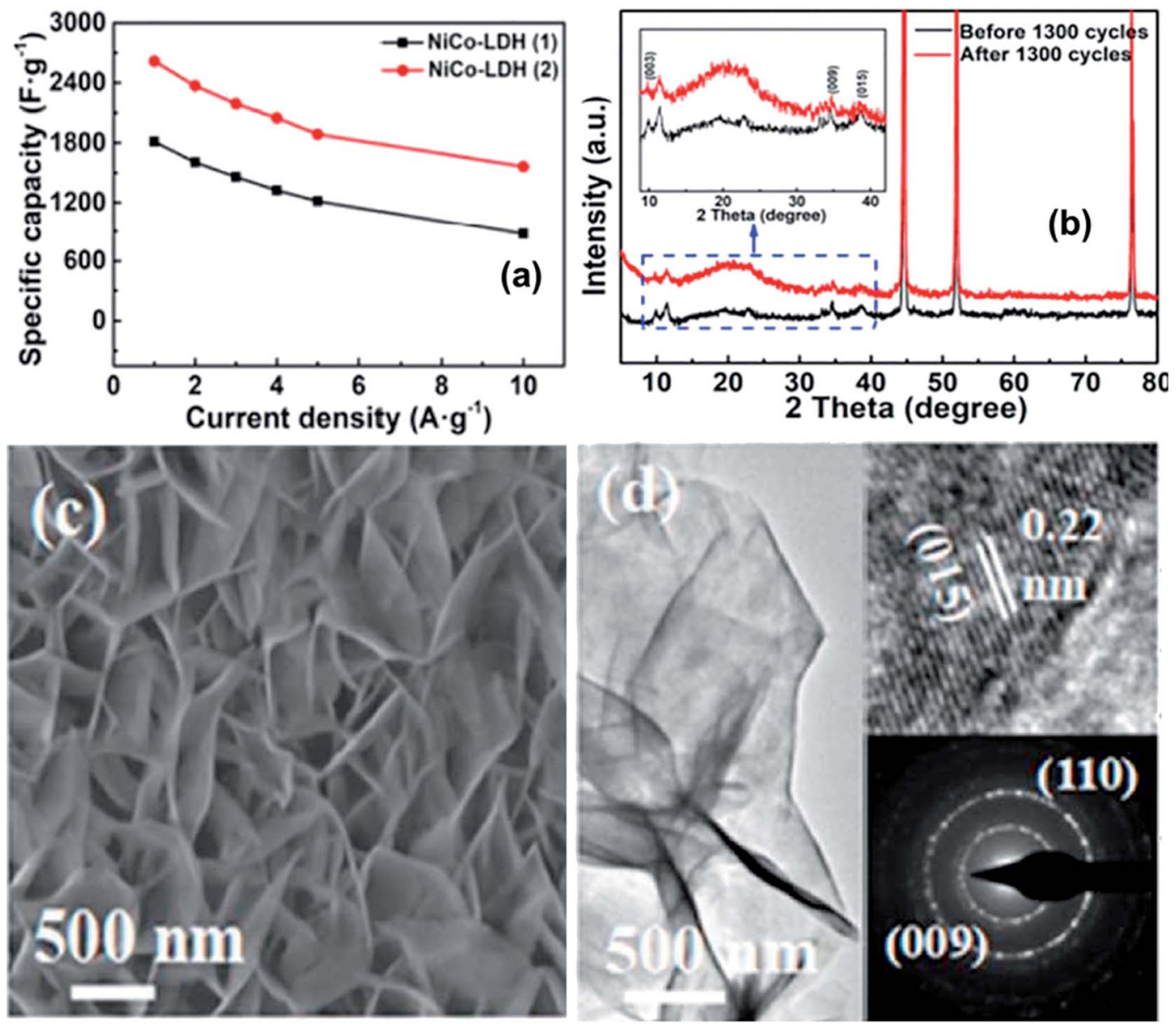

Fig. 11 (a) Specific capacitance of NiCo-LDH/NF ( $\alpha$ and $\beta$ ) at different current densities; (b) retention capacity; (c) comparison of the XRD patterns of NiCo-LDH/NF ( $\beta$ ) before and after the life cycles; ( $c$ and d) SEM and TEM images of NiCo-LDH/NF, respectively. Reproduced with the approval from ref. 24, Copyright 2019, Elsevier.

insertion and withdrawal of the charged species, shorten the ion transportation pathways and enable fast redox reactions and surface charge adsorption, which significantly increases the capacitance on the surface..$^{140-142}$

Jiang et al. prepared hollow nano-polyhedron LDHs by cobalt-based ZIF-67 to be used as a sacrificial model for electrode materials of supercapacitors with a specific capacitance of $1203 \mathrm{~F} \mathrm{~g}^{-1}$ at a current density of $1 \mathrm{~A} \mathrm{~g}^{-1} \cdot{ }^{131} \mathrm{Zhang}$ et al. obtained hollow porous $\mathrm{Co}_{3} \mathrm{O}_{4}$ via the process of calcination of the ZIF-67 precursor in the air, which contains a specific capacitance of $1100 \mathrm{~F} \mathrm{~g}^{-1}$ at the current density of $1.25 \mathrm{~A} \mathrm{~g}^{-1}$. $^{73}$ Xiao et al. described a hierarchical Ni/Co LDH microsphere obtained from MOFs, which reported a specific capacitance of $1652 \mathrm{~F} \mathrm{~g}^{-1}$ at a $\mathrm{Ni} / \mathrm{Co}$ ratio of $7 / 3 .^{143}$

Zheng et al. ${ }^{24}$ successfully synthesized 3D ultrathin nickelcobalt layered double hydroxide (NiCo-LDH) nanosheets that were vertically grown on $\mathrm{Ni}$ foam using a facile one-step hydrothermal route. The phase of NiCo-LDH can be tuned from a single $\alpha$ phase to multiphase ( $\alpha$ and $\beta$ ) simply by changing the volume ratio of the solvent. The multiphase NiCoLDH has superior electrochemical efficiency compared to the single alpha structure. The multiphase shows a larger specific capacitance of $2617 \mathrm{~F} \mathrm{~g}^{-1}$ at $1 \mathrm{~A} \mathrm{~g}^{-1}$, a better rate capacity of 60 percent at $10 \mathrm{~A} \mathrm{~g}^{-1}$ and enhanced cycling stability compared to the single alpha phase, which can be used as a promising positive material for supercapacitors. Additionally, an asymmetric supercapacitor device was developed for NiCo-LDH/NF/ $\mathrm{AC}$, which shows a high specific capacitance of $439.5 \mathrm{mF}$ $\mathrm{cm}^{-2}$ at $2 \mathrm{~mA} \mathrm{~cm}{ }^{-2}$ and good cycling stability (Fig. 11).

\subsection{Diverse ZIF-based nanostructures for supercapacitor electrodes}

Structural morphology contributes significantly to the transportation of electrons and ions to direct effect the capacitance and stability of electrodes. Lou et al. ${ }^{127}$ successfully prepared $\mathrm{Co}_{3} \mathrm{O}_{4} / \mathrm{NiCo}_{2} \mathrm{O}_{4}$ double-shelled nanocages with a box-in-box structure using the ZIF-67 precursor. The $\mathrm{Co}_{3} \mathrm{O}_{4} / \mathrm{NiCo}_{2} \mathrm{O}_{4}$ hybrid material showed greater performance compared to $\mathrm{Co}_{3} \mathrm{O}_{4}$, with a high specific capacitance of $1000 \mathrm{~F} \mathrm{~g}^{-1}$ at a current density of $5 \mathrm{~A} \mathrm{~g}^{-1}$ and $92.5 \%$ capacitance retention after 12000 cycles. The exclusive double-shelled structure may cause the electrolyte to be sandwiched between the shells; thus, a more rapid concentration can be anticipated, resulting in a greater driving force for electrochemical reactions. In other 
Table 5 Benefits of diverse nanostructures for high-performance supercapacitors

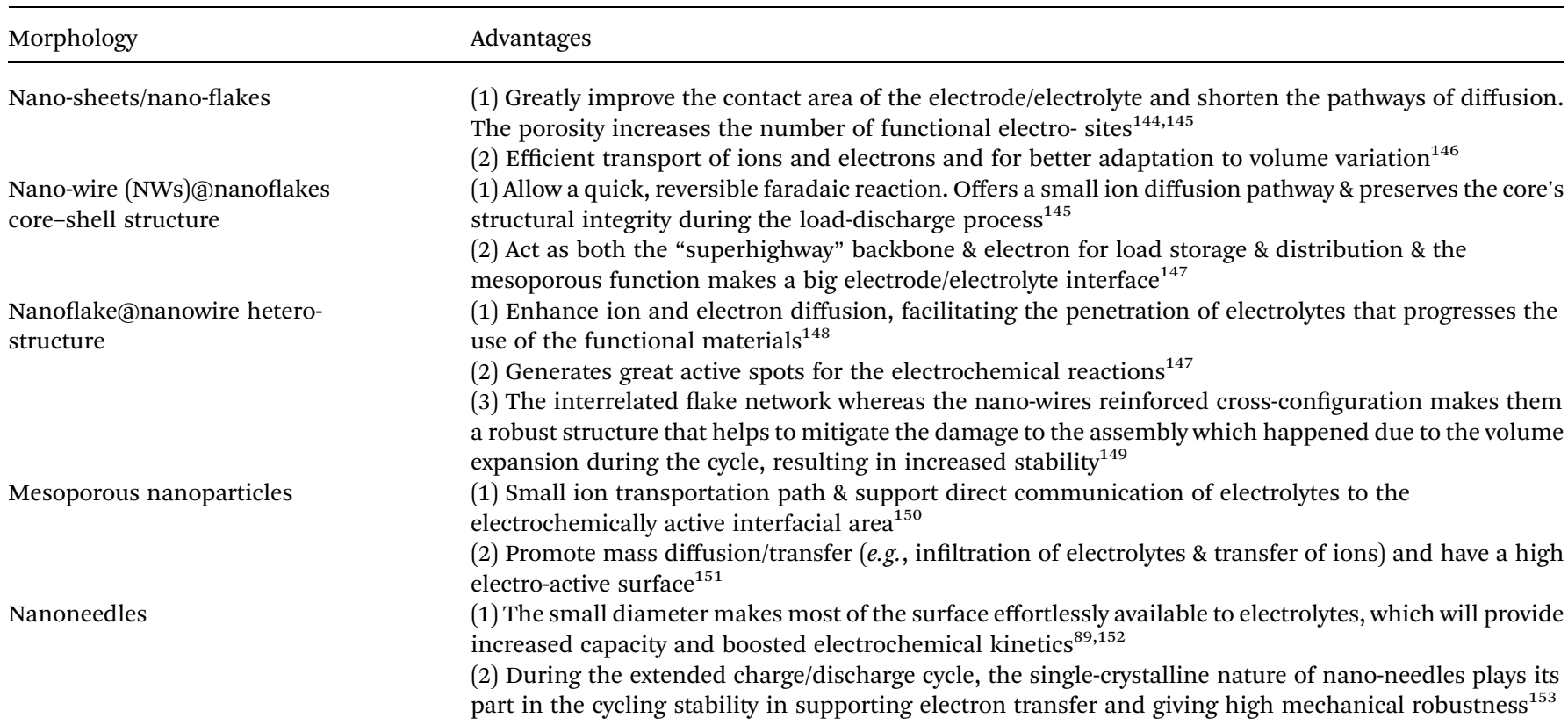

work, Yu et al. ${ }^{128}$ synthesized a core-shell nanowire array architecture in which $\mathrm{NiCo}_{2} \mathrm{O}_{4}$ nanoflakes were combined with $\mathrm{a} \mathrm{Co}_{3} \mathrm{O}_{4}$ nanowire substrate, and an increased energy density of $51 \mathrm{~W} \mathrm{~h} \mathrm{~kg}{ }^{-1}$ was observed at a power density of $860 \mathrm{~W} \mathrm{~kg}^{-1}$. However, it was found that a majority of the nanowires were wrecked and slanted in nanowire bunches and that the nanowire arrays lost their original structure while running the charge-discharge cycles, decreasing the cycling stability during long-term operation. To date, various morphologies have been investigated. Some of them are listed below in Table 5, and their benefits are also discussed.

\section{Conclusion and outlook}

ZIFs have become popular templates for the derivation of porous carbon, single/binary metal compounds, or their composites due to their designable compositions, tunable structures, controllable porosities, high surface areas, and bifunctionality with both sacrificial templates and metal precursors. Significant progress and achievements have been made in the design and development of ZIF-derived porous carbon, metal oxide materials, and their composites in the areas of micro/nano-structures, conductivity, stability, flexibility, capacitance, and stability, as shown in this review. The advantages of ZIF-derived materials as electrodes in supercapacitors are listed as follows:

For carbon-based materials:

(1) ZIF-derived PC materials not only have controlled porous structures and unique morphologies but also have excellent super capacitance behavior, such as specific capacitance, cycling stability and rate capability. Most ZIF-derived carbon electrodes do not require a conductive agent in their preparation.
(2) The large surface areas of ZIF-derived carbon and metal oxide-based materials increase the number of redox-active sites, which leads to close and strong contact at the electrode-electrolyte boundary.

(3) The large pore volume and hierarchical porous structure accelerate the distribution and migration of the ions of electrolytes. The porous hierarchy benefits electron and ion transport as well as mass diffusion and exchange.

(4) In N-doped ZIF-derived PC materials, the diverse nitrogen and oxygen functionalities not only enhance the surface properties and pseudocapacitance performance but also enhance the wettability of the inner structure of the microspores in the carbon electrodes.

(5) With the addition of carbon nanotubes, graphene, carbon nanofibers, or activated carbon, ZIF-derived carbon materials can be obtained, with improvements in areas such as extraordinary conductivity, good electrochemical steadiness, high strength, low density, and rapid charge-discharge procedures.

For metal oxides/hydroxides/sulfides-based materials:

(1) The porous and hollow structures of ZIF-derived metal oxide/hydroxide/sulfide or metallic compounds provide shortened pathways for the diffusion of electrolyte ions, thus promoting surface and near-surface redox reactions and remarkably enhancing the reaction kinetics and the long-term operational stability.

(2) The pseudo-capacitive performance, rate capability and cycling performance of ZIF-derived metallic compounds can be further increased by coupling with very conductive carbonbased substrates such as graphene, rGO, carbon nanosheets, or carbon nanotubes.

(3) The introduction of $\mathrm{S}^{2-}$ into the $\mathrm{O}^{2-}$ sites can efficiently promote the conductivity and electrochemical properties. 
(4) Through fine-tuning of the compositions of precursory ZIFs, spinel-type binary metal oxide-based compounds and nano-structured LDH electrodes can also be derived, which possess higher electrical conductivity and better redox capability compared with simple oxides and therefore hold potential for high-performance supercapacitors.

Although great progress has been made in the synthesis and applications of ZIF-based materials, more new synthesis strategies and utilization fields of ZIFs will undoubtedly emerge in the future. Their features of porous structures and tunable compositions offer the flexibility to design and prepare ZIF-derived nanomaterials with the desired catalytic active sites from the microscopic molecular level to macroscopic structural construction. This would include studies of their porous structure, the structural stability of metal dispersion in the precursor, metal diffusion during post-processing, suitability and controllability of template-based chemical reactions, and stability of catalytic activity for electrocatalysis. The variety of organic linkers and the diversity of link-link interactions offer rich chemistry to be developed and provide vast possibilities to form ZIFs with a wide range of structures and properties, which is a much larger area compared to conventional zeolites.

\section{Conflicts of interest}

There are no conflicts to declare.

\section{References}

1 C. Zhong, Y. Deng, W. Hu, J. Qiao, L. Zhang and J. Zhang, A review of electrolyte materials and compositions for electrochemical supercapacitors, Chem. Soc. Rev., 2015, 44, 7484-7539.

2 M. Winter and R. J. Brodd, What Are Batteries, Fuel Cells, and Supercapacitors?, Chem. Rev., 2004, 104, 4245-4270.

3 S. Guo and S. Dong, Graphene nanosheet: synthesis, molecular engineering, thin film, hybrids, and energy and analytical applications, Chem. Soc. Rev., 2011, 40, 26442672.

4 B. E. Conway, Electrochemical supercapacitors: scientific fundamentals and technological applications, Springer Science \& Business Media, 2013.

5 M. Pumera, Graphene-based nanomaterials for energy storage, Energy Environ. Sci., 2011, 4, 668-674.

6 J.-G. Wang, F. Kang and B. Wei, Engineering of $\mathrm{MnO}_{2}$-based nanocomposites for high-performance supercapacitors, Prog. Mater. Sci., 2015, 74, 51-124.

7 P. Sennu, V. Aravindan and Y.-S. Lee, High energy asymmetric supercapacitor with 1D@ 2D structured $\mathrm{NiCo}_{2} \mathrm{O}_{4} @ \mathrm{Co}_{3} \mathrm{O}_{4}$ and jackfruit derived high surface area porous carbon, J. Power Sources, 2016, 306, 248-257.

8 F. Béguin, V. Presser, A. Balducci and E. Frackowiak, Carbons and electrolytes for advanced supercapacitors, Adv. Mater., 2014, 26, 2219-2251.

9 X. Wang, X. Cao, L. Bourgeois, H. Guan, S. Chen, Y. Zhong, D. M. Tang, H. Li, T. Zhai and L. Li, N-doped graphene-SnO sandwich paper for high-performance lithium-ion batteries, Adv. Funct. Mater., 2012, 22, 2682-2690.

10 Z. Yang, J. Zhang, M. C. Kintner-Meyer, X. Lu, D. Choi, J. P. Lemmon and J. Liu, Electrochemical energy storage for green grid, Chem. Rev., 2011, 111, 3577-3613.

11 P. Simon and Y. Gogotsi, Capacitive energy storage in nanostructured carbon-electrolyte systems, Acc. Chem. Res., 2013, 46, 1094-1103.

12 A. Ghosh and Y. H. Lee, Carbon-based electrochemical capacitors, ChemSusChem, 2012, 5, 480-499.

13 H. I. Becker, Low voltage electrolytic capacitor, US Pat., US2800616A, 1957.

14 F. Shi, L. Li, X.-l. Wang, C.-d. Gu and J.-p. Tu, Metal oxide/ hydroxide-based materials for supercapacitors, RSC Adv., 2014, 4, 41910-41921.

$15 \mathrm{~J}$. Chen, C. Li and G. Shi, Graphene materials for electrochemical capacitors, J. Phys. Chem. Lett., 2013, 4, 1244-1253.

16 Z. Chen, V. Augustyn, J. Wen, Y. Zhang, M. Shen, B. Dunn and Y. Lu, High-performance supercapacitors based on intertwined $\mathrm{CNT} / \mathrm{V}_{2} \mathrm{O}_{5}$ nanowire nanocomposites, Adv. Mater., 2011, 23, 791-795.

17 D. Dubal, D. S. Dhawale, R. Salunkhe and C. Lokhande, Conversion of interlocked cube-like $\mathrm{Mn}_{3} \mathrm{O}_{4}$ into nanoflakes of layered birnessite $\mathrm{MnO}_{2}$ during supercapacitive studies, J. Alloys Compd., 2010, 496, 370375.

18 X. Wang, W. Tian, T. Zhai, C. Zhi, Y. Bando and D. Golberg, Cobalt (II, III) oxide hollow structures: fabrication, properties and applications, J. Mater. Chem., 2012, 22, 23310-23326.

19 Y. Wen, C. Huang, L. Wang and D. Hulicova-Jurcakova, Heteroatom-doped graphene for electrochemical energy storage, Chin. Sci. Bull., 2014, 59, 2102-2121.

20 H. v. Helmholtz, Ueber einige Gesetze der Vertheilung elektrischer Ströme in körperlichen Leitern, mit Anwendung auf die thierisch-elektrischen Versuche (Schluss.), Ann. Phys., 1853, 165, 353-377.

$21 \mathrm{M}$. Gouy, Sur la constitution de la charge électrique à la surface d'un électrolyte, J. Phys. Theor. Appl., 1910, 9, 457468.

22 E. Zhou, C. Wang, Q. Zhao, Z. Li, M. Shao, X. Deng, X. Liu and $\mathrm{X} . \mathrm{Xu}$, Facile synthesis of $\mathrm{MoO}_{2}$ nanoparticles as high performance supercapacitor electrodes and photocatalysts, Ceram. Int., 2016, 42, 2198-2203.

23 W. He, W. Yang, C. Wang, X. Deng, B. Liu and X. Xu, Morphology-controlled syntheses of $\alpha-\mathrm{MnO}_{2}$ for electrochemical energy storage, Phys. Chem. Chem. Phys., 2016, 18, 15235-15243.

24 H. Xing, Y. Lan, Y. Zong, Y. Sun, X. Zhu, X. Li and X. Zheng, Ultrathin NiCo-layered double hydroxide nanosheets arrays vertically grown on $\mathrm{Ni}$ foam as binder-free highperformance supercapacitors, Inorg. Chem. Commun., 2019, 101, 125-129.

25 S. Biswas, A. Chowdhury and A. Chandra, Performance of Na-ion Supercapacitors Under Non-ambient Conditions- 
From Temperature to Magnetic Field Dependent Variation in Specific Capacitance, Front. Mater., 2019, 6, 1-11.

26 S. Biswas, V. Sharma, D. Mandal, A. Chowdhury, M. Chakravarty, S. Priya, C. C. Gowda, P. De, I. Singh and A. Chandra, Hollow nanostructures of metal oxides as emerging electrode materials for high performance supercapacitors, CrystEngComm, 2020, 22, 1633-1644.

27 M. A. Akhtar, V. Sharma, S. Biswas and A. Chandra, Tuning porous nanostructures of $\mathrm{MnCo}_{2} \mathrm{O}_{4}$ for application in supercapacitors and catalysis, RSC Adv., 2016, 6, 9629696305.

28 R. Kötz and M. Carlen, Principles and applications of electrochemical capacitors, Electrochim. Acta, 2000, 45, 2483-2498.

29 E. Frackowiak, S. Delpeux, K. Jurewicz, K. Szostak, D. Cazorla-Amoros and F. Béguin, Enhanced capacitance of carbon nanotubes through chemical activation, Chem. Phys. Lett., 2002, 361, 35-41.

30 J. L. Rowsell and O. M. Yaghi, Metal-organic frameworks: a new class of porous materials, Microporous Mesoporous Mater., 2004, 73, 3-14.

31 W. Li, N. Islam, S. Azam, Z. Xu, J. Warzywoda and Z. Fan, ZIF-67-derived edge-oriented graphene clusters coupled with carbon nanotubes containing encapsulated Co nanoparticles for high-frequency electrochemical capacitors, Sustainable Energy Fuels, 2019, 3, 3029-3037.

32 Z. Wang, T. Yan, J. Fang, L. Shi and D. Zhang, Nitrogendoped porous carbon derived from a bimetallic metalorganic framework as highly efficient electrodes for flowthrough deionization capacitors, J. Mater. Chem. A, 2016, 4, 10858-10868.

33 L. Zhao, A. Yang, A. Wang, H. Yu, J. Dai and Y. Zheng, ZIF-67 derived $\mathrm{Co}, \mathrm{Fe}$, Ni co-doped porous carbon as an efficient electrocatalyst for hydrogen evolution reaction, $J$. Porous Mater., 2020, 27, 1685-1690.

34 C. Largeot, C. Portet, J. Chmiola, P.-L. Taberna, Y. Gogotsi and P. Simon, Relation between the Ion Size and Pore Size for an Electric Double-Layer Capacitor, J. Am. Chem. Soc., 2008, 130, 2730-2731.

35 L. Wan, E. Shamsaei, C. D. Easton, D. Yu, Y. Liang, X. Chen, Z. Abbasi, A. Akbari, X. Zhang and H. Wang, ZIF-8 derived nitrogen-doped porous carbon/carbon nanotube composite for high-performance supercapacitor, Carbon, 2017, 121, 330-336.

36 M. Jiang, X. Cao, D. Zhu, Y. Duan and J. Zhang, Hierarchically Porous N-doped Carbon Derived from ZIF-8 Nanocomposites for Electrochemical Applications, Electrochim. Acta, 2016, 196, 699-707.

37 S. Zhong, C. Zhan and D. Cao, Zeolitic imidazolate framework-derived nitrogen-doped porous carbons as high performance supercapacitor electrode materials, Carbon, 2015, 85, 51-59.

38 W. Chaikittisilp, K. Ariga and Y. Yamauchi, A new family of carbon materials: synthesis of MOF-derived nanoporous carbons and their promising applications, J. Mater. Chem. A, 2013, 1, 14-19.
39 Y. Xue, S. Zheng, H. Xue and H. Pang, Metal-organic framework composites and their electrochemical applications, J. Mater. Chem. A, 2019, 7, 7301-7327.

40 R. Ahmad, N. Iqbal, M. M. Baig, T. Noor, G. Ali and I. H. Gul, ZIF-67 derived NCNT/S@Ni(OH $)_{2}$ decorated Ni foam based electrode material for high-performance supercapacitors, Electrochim. Acta, 2020, 137147.

41 S. Hanif, X. Shi, N. Iqbal, T. Noor, R. Anwar and A. M. Kannan, ZIF derived PtNiCo/NC cathode catalyst for proton exchange membrane fuel cell, Appl. Catal., B, 2019, 258, 117947.

42 S. Hanif, N. Iqbal, X. Shi, T. Noor, G. Ali and A. M. Kannan, NiCo-N-doped carbon nanotubes based cathode catalyst for alkaline membrane fuel cell, Renewable Energy, 2020, 154, 508-516.

43 L. Yaqoob, T. Noor, N. Iqbal, H. Nasir, M. Sohail, N. Zaman and M. Usman, Nanocomposites of cobalt benzene tricarboxylic acid MOF with rGO: an efficient and robust electrocatalyst for oxygen evolution reaction (OER), Renewable Energy, 2020, 156, 1040-1054.

44 L. Aftab, N. Iqbal, A. Asghar and T. Noor, Synthesis, characterization and gas adsorption analysis of solvent dependent Zn-BTC metal organic frameworks, Sep. Sci. Technol., 2020, 1-11.

45 T. Noor, S. Pervaiz, N. Iqbal, H. Nasir, N. Zaman, M. Sharif and E. Pervaiz, Nanocomposites of $\mathrm{NiO} / \mathrm{CuO}$ Based MOF with rGO: An Efficient and Robust Electrocatalyst for Methanol Oxidation Reaction in DMFC, Nanomaterials, 2020, 10, 1601.

46 A. Wahab, N. Iqbal, T. Noor, S. Ashraf, M. A. Raza, A. Ahmad and U. A. Khan, Thermally reduced mesoporous manganese MOF @reduced graphene oxide nanocomposite as bifunctional electrocatalyst for oxygen reduction and evolution, $R S C A d v ., 2020$, 10, 27728-27742.

47 R. Anwar, N. Iqbal, S. Hanif, T. Noor, X. Shi, N. Zaman, D. Haider, S. A. M. Rizvi and A. M. Kannan, MOF-Derived CuPt/NC Electrocatalyst for Oxygen Reduction Reaction, Catalysts, 2020, 10, 799.

48 M. D. Haider, N. Iqbal, S. A. M. Rizvi, T. Noor, S. Hanif and R. Anwar, ZIF-67 Derived Cu-Doped Electrocatalyst for Oxygen Reduction Reaction, J. Electrochem. Energy Convers. Storage, 2020, 18, 021001.

49 A. Asghar, N. Iqbal, L. Aftab, T. Noor, B. M. Kariuki, L. Kidwell and T. L. Easun, Ethylenediamine loading into a manganese-based metal-organic framework enhances water stability and carbon dioxide uptake of the framework, R. Soc. Open Sci., 2020, 7, 191934.

50 A. Asghar, N. Iqbal and T. Noor, Ultrasonication treatment enhances MOF surface area and gas uptake capacity, Polyhedron, 2020, 181, 114463.

51 S. A. M. Rizvi, N. Iqbal, M. D. Haider, T. Noor, R. Anwar and S. Hanif, Synthesis and Characterization of Cu-MOF Derived Cu@AC Electrocatalyst for Oxygen Reduction Reaction in PEMFC, Catal. Lett., 2019, 150, 1397-1407.

52 J. Khan, N. Iqbal, A. Asghar and T. Noor, Novel amine functionalized metal organic framework synthesis for 
enhanced carbon dioxide capture, Mater. Res. Express, 2019, 6, 105539.

53 R. Mehek, N. Iqbal, T. Noor, H. Nasir, Y. Mehmood and S. Ahmed, Novel Co-MOF/Graphene Oxide Electrocatalyst for Methanol Oxidation, Electrochim. Acta, 2017, 255, 195204.

54 R. Ahmad, N. Iqbal and T. Noor, Development of ZIFDerived Nanoporous Carbon and Cobalt Sulfide-Based Electrode Material for Supercapacitor, Materials, 2019, 12, 2940.

55 X. Shi, N. Iqbal, S. S. Kunwar, G. Wahab, H. A. Kasat and A. M. Kannan, PtCo@NCNTs cathode catalyst using ZIF67 for proton exchange membrane fuel cell, Int. J. Hydrogen Energy, 2018, 43, 3520-3526.

56 L. Yaqoob, T. Noor, N. Iqbal, H. Nasir and N. Zaman, Development of Nickel-BTC-MOF-Derived Nanocomposites with rGO Towards Electrocatalytic Oxidation of Methanol and Its Product Analysis, Catalysts, 2019, 9, 856.

57 T. Noor, N. Zaman, H. Nasir, N. Iqbal and Z. Hussain, Electro catalytic study of NiO-MOF/rGO composites for methanol oxidation reaction, Electrochim. Acta, 2019, 307, $1-12$.

58 T. Noor, M. Ammad, N. Zaman, N. Iqbal, L. Yaqoob and H. Nasir, A Highly Efficient and Stable Copper BTC Metal Organic Framework Derived Electrocatalyst for Oxidation of Methanol in DMFC Application, Catal. Lett., 2019, 149, 3312-3327.

59 M. Oh and C. A. Mirkin, Chemically tailorable colloidal particles from infinite coordination polymers, Nature, 2005, 438, 651-654.

60 R. R. Salunkhe, Y. V. Kaneti and Y. Yamauchi, MetalOrganic Framework-Derived Nanoporous Metal Oxides toward Supercapacitor Applications: Progress and Prospects, ACS Nano, 2017, 11, 5293-5308.

61 H.-L. Jiang, B. Liu, Y.-Q. Lan, K. Kuratani, T. Akita, H. Shioyama, F. Zong and Q. Xu, From Metal-Organic Framework to Nanoporous Carbon: Toward a Very High Surface Area and Hydrogen Uptake, J. Am. Chem. Soc., 2011, 133, 11854-11857.

62 B. Liu, H. Shioyama, T. Akita and Q. Xu, Metal-organic framework as a template for porous carbon synthesis, $J$. Am. Chem. Soc., 2008, 130, 5390-5391.

63 J. Tang, R. R. Salunkhe, J. Liu, N. L. Torad, M. Imura, S. Furukawa and Y. Yamauchi, Thermal Conversion of Core-Shell Metal-Organic Frameworks: A New Method for Selectively Functionalized Nanoporous Hybrid Carbon, $J$. Am. Chem. Soc., 2015, 137, 1572-1580.

64 N. Stock and S. Biswas, Synthesis of metal-organic frameworks (MOFs): routes to various MOF topologies, morphologies, and composites, Chem. Rev., 2012, 112, 933-969.

65 T. Kyotani, T. Nagai, S. Inoue and A. Tomita, Formation of New Type of Porous Carbon by Carbonization in Zeolite Nanochannels, Chem. Mater., 1997, 9, 609-615.

66 N. L. Torad, M. Hu, Y. Kamachi, K. Takai, M. Imura, M. Naito and Y. Yamauchi, Facile synthesis of nanoporous carbons with controlled particle sizes by direct carbonization of monodispersed ZIF-8 crystals, Chem. Commun., 2013, 49, 2521-2523.

67 W. Chaikittisilp, M. Hu, H. Wang, H.-S. Huang, T. Fujita, K. C.-W. Wu, L.-C. Chen, Y. Yamauchi and K. Ariga, Nanoporous carbons through direct carbonization of a zeolitic imidazolate framework for supercapacitor electrodes, Chem. Commun., 2012, 48, 7259-7261.

68 F. Marpaung, M. Kim, J. H. Khan, K. Konstantinov, Y. Yamauchi, M. S. A. Hossain, J. Na and J. Kim, MetalOrganic Framework (MOF)-Derived Nanoporous Carbon Materials, Chem.-Asian J., 2019, 14, 1331-1343.

69 R. R. Salunkhe, Y. V. Kaneti, J. Kim, J. H. Kim and Y. Yamauchi, Nanoarchitectures for metal-organic framework-derived nanoporous carbons toward supercapacitor applications, Acc. Chem. Res., 2016, 49, 2796-2806.

70 R. Ahmad, N. Iqbal, M. M. Baig, T. Noor, G. Ali and I. H. Gul, ZIF-67 derived nitrogen doped CNTs decorated with sulfur and $\mathrm{Ni}(\mathrm{OH})_{2}$ as potential electrode material for highperformance supercapacitors, Electrochim. Acta, 2020, 364, 137147.

71 J. Qian, F. Sun and L. Qin, Hydrothermal synthesis of zeolitic imidazolate framework-67 (ZIF-67) nanocrystals, Mater. Lett., 2012, 82, 220-223.

72 J. Tang, R. R. Salunkhe, H. Zhang, V. Malgras, T. Ahamad, S. M. Alshehri, N. Kobayashi, S. Tominaka, Y. Ide, J. H. Kim and Y. Yamauchi, Bimetallic Metal-Organic Frameworks for Controlled Catalytic Graphitization of Nanoporous Carbons, Sci. Rep., 2016, 6, 30295.

73 Y.-Z. Zhang, Y. Wang, Y.-L. Xie, T. Cheng, W.-Y. Lai, H. Pang and W. Huang, Porous hollow $\mathrm{Co}_{3} \mathrm{O}_{4}$ with rhombic dodecahedral structures for high-performance supercapacitors, Nanoscale, 2014, 6, 14354-14359.

74 R. Tian, Y. Zhou, H. Duan, Y. Guo, H. Li, K. Chen, D. Xue and H. Liu, MOF-Derived Hollow $\mathrm{Co}_{3} \mathrm{~S}_{4}$ Quasi-polyhedron/ MWCNT Nanocomposites as Electrodes for Advanced Lithium Ion Batteries and Supercapacitors, ACS Appl. Energy Mater., 2018, 1, 402-410.

75 X. Wang, J. Zhou, H. Fu, W. Li, X. Fan, G. Xin, J. Zheng and X. Li, MOF derived catalysts for electrochemical oxygen reduction, J. Mater. Chem. A, 2014, 2, 14064-14070.

76 W. Xia, R. Zou, L. An, D. Xia and S. Guo, A metal-organic framework route to in situ encapsulation of $\mathrm{Co@} \mathrm{Co}_{3} \mathrm{O}_{4}$ @ C core@ bishell nanoparticles into a highly ordered porous carbon matrix for oxygen reduction, Energy Environ. Sci., 2015, 8, 568-576.

77 H. Yi, H. Wang, Y. Jing, T. Peng and X. Wang, Asymmetric supercapacitors based on carbon nanotubes@ NiO ultrathin nanosheets core-shell composites and MOFderived porous carbon polyhedrons with super-long cycle life, J. Power Sources, 2015, 285, 281-290.

78 J. Kim, C. Young, J. Lee, M.-S. Park, M. Shahabuddin, Y. Yamauchi and J. H. Kim, CNTs grown on nanoporous carbon from zeolitic imidazolate frameworks for supercapacitors, Chem. Commun., 2016, 52, 13016-13019. 
79 X. Cao, C. Tan, M. Sindoro and H. Zhang, Hybrid micro-/ nano-structures derived from metal-organic frameworks: preparation and applications in energy storage and conversion, Chem. Soc. Rev., 2017, 46, 2660-2677.

80 S. J. Yang, T. Kim, J. H. Im, Y. S. Kim, K. Lee, H. Jung and C. R. Park, MOF-derived hierarchically porous carbon with exceptional porosity and hydrogen storage capacity, Chem. Mater., 2012, 24, 464-470.

81 S. Xu, Y. Lv, X. Zeng and D. Cao, ZIF-derived nitrogen-doped porous carbons as highly efficient adsorbents for removal of organic compounds from wastewater, Chem. Eng. J., 2017, 323, 502-511.

82 R. R. Salunkhe, Y. Kamachi, N. L. Torad, S. M. Hwang, Z. Sun, S. X. Dou, J. H. Kim and Y. Yamauchi, Fabrication of symmetric supercapacitors based on MOF-derived nanoporous carbons, J. Mater. Chem. A, 2014, 2, 1984819854.

83 R. R. Salunkhe, J. Tang, Y. Kamachi, T. Nakato, J. H. Kim and Y. Yamauchi, Asymmetric supercapacitors using 3D nanoporous carbon and cobalt oxide electrodes synthesized from a single metal-organic framework, ACS Nano, 2015, 9, 6288-6296.

84 F. Zhang, L. Hao, L. Zhang and X. Zhang, Solid-state thermolysis preparation of $\mathrm{Co}_{3} \mathrm{O}_{4}$ nano/micro superstructures from metal-organic framework for supercapacitors, Int. J. Electrochem. Sci., 2011, 6, 2943-2954.

85 C. Guan, W. Zhao, Y. Hu, Z. Lai, X. Li, S. Sun, H. Zhang, A. K. Cheetham and J. Wang, Cobalt oxide and N-doped carbon nanosheets derived from a single two-dimensional metal-organic framework precursor and their application in flexible asymmetric supercapacitors, Nanoscale Horiz., 2017, 2, 99-105.

86 Q. Wang, W. Xia, W. Guo, L. An, D. Xia and R. Zou, Functional zeolitic-imidazolate-framework-templated porous carbon materials for $\mathrm{CO}_{2}$ capture and enhanced capacitors, Chem.-Asian J., 2013, 8, 1879-1885.

87 A. J. Amali, J.-K. Sun and Q. Xu, From assembled metalorganic framework nanoparticles to hierarchically porous carbon for electrochemical energy storage, Chem. Commun., 2014, 50, 1519-1522.

88 F. Martin-Jimeno, F. Suarez-Garcia, J. Paredes, M. Enterria, M. Pereira, J. Martins, J. Figueiredo, A. Martinez-Alonso and J. Tascon, A "nanopore lithography" strategy for synthesizing hierarchically micro/mesoporous carbons from ZIF-8/graphene oxide hybrids for electrochemical energy storage, ACS Appl. Mater. Interfaces, 2017, 9, 4474044755.

89 S. Hou, G. Zhang, W. Zeng, J. Zhu, F. Gong, F. Li and H. Duan, Hierarchical Core-Shell Structure of $\mathrm{ZnO}$ Nanorod@NiO/ $\mathrm{MoO}_{2}$ Composite Nanosheet Arrays for High-Performance Supercapacitors, ACS Appl. Mater. Interfaces, 2014, 6, 13564-13570.

90 C. Young, R. R. Salunkhe, J. Tang, C.-C. Hu, M. Shahabuddin, E. Yanmaz, M. S. A. Hossain, J. H. Kim and Y. Yamauchi, Zeolitic imidazolate framework (ZIF-8) derived nanoporous carbon: the effect of carbonization temperature on the supercapacitor performance in an aqueous electrolyte, Phys. Chem. Chem. Phys., 2016, 18, 29308-29315.

91 J. Huang, F. Hao, X. Zhang and J. Chen, N-doped porous carbon sheets derived from ZIF-8: preparation and their electrochemical capacitive properties, J. Electroanal. Chem., 2018, 810, 86-94.

92 C. Wang, C. Liu, J. Li, X. Sun, J. Shen, W. Han and L. Wang, Electrospun metal-organic framework derived hierarchical carbon nanofibers with high performance for supercapacitors, Chem. Commun., 2017, 53, 1751-1754.

93 C. Li, C. Hu, Y. Zhao, L. Song, J. Zhang, R. Huang and L. Qu, Decoration of graphene network with metal-organic frameworks for enhanced electrochemical capacitive behavior, Carbon, 2014, 78, 231-242.

94 T. Gao, F. Zhou, W. Ma and H. Li, Metal-organic-framework derived carbon polyhedron and carbon nanotube hybrids as electrode for electrochemical supercapacitor and capacitive deionization, Electrochim. Acta, 2018, 263, 85-93.

95 Y. Wang, B. Chen, Y. Zhang, L. Fu, Y. Zhu, L. Zhang and Y.Wu, ZIF-8@ MWCNT-derived carbon composite as electrode of high performance for supercapacitor, Electrochim. Acta, 2016, 213, 260-269.

96 X. Li, C. Hao, B. Tang, Y. Wang, M. Liu, Y. Wang, Y. Zhu, C. Lu and Z. Tang, Supercapacitor electrode materials with hierarchically structured pores from carbonization of MWCNTs and ZIF-8 composites, Nanoscale, 2017, 9, 21782187.

97 Y. Zhang, B. Lin, J. Wang, J. Tian, Y. Sun, X. Zhang and H. Yang, All-solid-state asymmetric supercapacitors based on ZnO quantum dots/carbon/CNT and porous N-doped carbon/CNT electrodes derived from a single ZIF-8/CNT template, J. Mater. Chem. A, 2016, 4, 10282-10293.

98 R. R. Salunkhe, J. Tang, N. Kobayashi, J. Kim, Y. Ide, S. Tominaka, J. H. Kim and Y. Yamauchi, Ultrahigh performance supercapacitors utilizing core-shell nanoarchitectures from a metal-organic frameworkderived nanoporous carbon and a conducting polymer, Chem. Sci., 2016, 7, 5704-5713.

99 Y. Liu, X. Xu and Z. Shao, Metal-organic frameworks derived porous carbon, metal oxides and metal sulfides-based compounds for supercapacitors application, Energy Storage Mater., 2020, 26, 1-22.

100 Y. Lei, M. Gan, L. Ma, M. Jin, X. Zhang, G. Fu, P. Yang and M. Yan, Synthesis of nitrogen-doped porous carbon from zeolitic imidazolate framework-67 and phenolic resin for high performance supercapacitors, Ceram. Int., 2017, 43, 6502-6510.

101 P. Zhang, F. Sun, Z. Shen and D. Cao, ZIF-derived porous carbon: a promising supercapacitor electrode material, $J$. Mater. Chem. A, 2014, 2, 12873-12880.

102 X. Deng, S. Zhu, J. Li, L. Ma, F. He, E. Liu, C. He, C. Shi, Q. Li and N. Zhao, Ball-in-cage nanocomposites of metalorganic frameworks and three-dimensional carbon networks: synthesis and capacitive performance, Nanoscale, 2017, 9, 6478-6485.

103 L. Xin, R. Chen, Q. Liu, J. Liu, Z. Li, R. Li and J. Wang, Composites of hierarchical metal-organic framework 
derived nitrogen-doped porous carbon and interpenetrating 3D hollow carbon spheres from lotus pollen for high-performance supercapacitors, New J. Chem., 2017, 41, 12835-12842.

104 B. Han, G. Cheng, E. Zhang, L. Zhang and X. Wang, Three dimensional hierarchically porous ZIF-8 derived carbon/ LDH core-shell composite for high performance supercapacitors, Electrochim. Acta, 2018, 263, 391-399.

105 R. R. Salunkhe, C. Young, J. Tang, T. Takei, Y. Ide, N. Kobayashi and Y. Yamauchi, A high-performance supercapacitor cell based on ZIF-8-derived nanoporous carbon using an organic electrolyte, Chem. Commun., 2016, 52, 4764-4767.

106 S. Nagamuthu and K.-S. Ryu, MOF-derived microstructural interconnected network porous $\mathrm{Mn}_{2} \mathrm{O}_{3} / \mathrm{C}$ as negative electrode material for asymmetric supercapacitor device, CrystEngComm, 2019, 21, 1442-1451.

107 X. Deng, J. Li, S. Zhu, F. He, C. He, E. Liu, C. Shi, Q. Li and N. Zhao, Metal-organic frameworks-derived honeycomblike $\mathrm{Co}_{3} \mathrm{O}_{4} /$ three-dimensional graphene networks/Ni foam hybrid as a binder-free electrode for supercapacitors, $J$. Alloys Compd., 2017, 693, 16-24.

108 G. Huang, F. Zhang, X. Du, Y. Qin, D. Yin and L. Wang, Metal organic frameworks route to in situ insertion of multiwalled carbon nanotubes in $\mathrm{Co}_{3} \mathrm{O}_{4}$ polyhedra as anode materials for lithium-ion batteries, ACS Nano, 2015, 9, 1592-1599.

109 M. Azad, Z. Hussain and M. M. Baig, MWCNTs/NiS decorated Ni foam based electrode for high-performance supercapacitors, Electrochim. Acta, 2020, 345, 136196.

110 M. M. Baig, I. H. Gul, M. Z. Khan, M. T. Mehran and M. S. Akhtar, Binder-free heterostructured MWCNTs/ $\mathrm{Al}_{2} \mathrm{~S}_{3}$ decorated on NiCo foam as highly reversible cathode material for high-performance supercapacitors, Electrochim. Acta, 2020, 340, 135955.

111 M. M. Baig, E. Pervaiz, M. Yang and I. H. Gul, HighPerformance Supercapacitor Electrode Obtained By Directly Bonding 2D Materials: Hierarchical $\mathrm{MoS}_{2}$ on Reduced Graphene Oxide, Front. Mater., 2020, 7, 323.

112 S. Han, S. C. Warren, S. M. Yoon, C. D. Malliakas, X. Hou, Y. Wei, M. G. Kanatzidis and B. A. Grzybowski, Tunneling electrical connection to the interior of metal-organic frameworks, J. Am. Chem. Soc., 2015, 137, 8169-8175.

113 H. Liu, H. Guo, L. Yue, N. Wu, Q. Li, W. Yao, R. Xue, M. Wang and W. Yang, Metal-Organic Frameworks-Derived $\quad \mathrm{NiS}_{2} / \mathrm{CoS}_{2} / \mathrm{N}$-Doped Carbon Composites as Electrode Materials for Asymmetric Supercapacitor, ChemElectroChem, 2019, 6, 3764-3773.

114 D. Tian, S. Chen, W. Zhu, C. Wang and X. Lu, Metal-organic framework derived hierarchical $\mathrm{Ni} / \mathrm{Ni}_{3} \mathrm{~S}_{2}$ decorated carbon nanofibers for high-performance supercapacitors, Mater. Chem. Front., 2019, 3, 1653-1660.

115 J. S. Chen, C. Guan, Y. Gui and D. J. Blackwood, Rational design of self-supported $\mathrm{Ni}_{3} \mathrm{~S}_{2}$ nanosheets array for advanced asymmetric supercapacitor with a superior energy density, ACS Appl. Mater. Interfaces, 2017, 9, 496504.
116 X. Y. Yu, L. Yu, H. B. Wu and X. W. Lou, Formation of nickel sulfide nanoframes from metal-organic frameworks with enhanced pseudocapacitive and electrocatalytic properties, Angew. Chem., 2015, 127, 5421-5425.

117 Y. Liu, Z. Wang, Y. Zhong, M. Tade, W. Zhou and Z. Shao, Molecular design of mesoporous $\mathrm{NiCo}_{2} \mathrm{O}_{4}$ and $\mathrm{NiCo}_{2} \mathrm{~S}_{4}$ with sub-micrometer-polyhedron architectures for efficient pseudocapacitive energy storage, Adv. Funct. Mater., 2017, 27, 1701229.

118 J. Yu, X. Gao, Z. Cui, Y. Jiao, Q. Zhang, H. Dong, L. Yu and L. Dong, Facile synthesis of binary transition metal sulfide tubes derived from NiCo-MOF-74 for high-performance supercapacitors, Energy Technol., 2019, 7, 1900018.

119 H. Hu, B. Y. Guan and X. W. D. Lou, Construction of complex CoS hollow structures with enhanced electrochemical properties for hybrid supercapacitors, Chem, 2016, 1, 102-113.

120 X. Han, K. Tao, D. Wang and L. Han, Design of a porous cobalt sulfide nanosheet array on $\mathrm{Ni}$ foam from zeolitic imidazolate frameworks as an advanced electrode for supercapacitors, Nanoscale, 2018, 10, 2735-2741.

121 J. Liu, C. Wu, D. Xiao, P. Kopold, L. Gu, P. A. van Aken, J. Maier and Y. Yu, MOF-derived hollow Co9S8 nanoparticles embedded in graphitic carbon nanocages with superior Li-ion storage, Small, 2016, 12, 2354-2364.

122 Z. Sun, F. Huang, Y. Sui, F. Wei, J. Qi, Q. Meng, H. Hu and Y. He, Cobalt oxide composites derived from zeolitic imidazolate framework for high-performance supercapacitor electrode, J. Mater. Sci.: Mater. Electron., 2017, 28, 14019-14025.

123 B. Wang, W. Tan, R. Fu, H. Mao, Y. Kong, Y. Qin and Y. Tao, Hierarchical mesoporous $\mathrm{Co}_{3} \mathrm{O}_{4} / \mathrm{C} @ \mathrm{MoS}_{2}$ core-shell structured materials for electrochemical energy storage with high supercapacitive performance, Synth. Met., 2017, 233, 101-110.

124 H. Tabassum, A. Mahmood, Q. Wang, W. Xia, Z. Liang, B. Qiu and R. Zou, Hierarchical cobalt hydroxide and B/N co-doped graphene nanohybrids derived from metalorganic frameworks for high energy density asymmetric supercapacitors, Sci. Rep., 2017, 7, 43084.

125 X. Bai, J. Liu, Q. Liu, R. Chen, X. Jing, B. Li and J. Wang, In-Situ Fabrication of MOF-Derived Co- Co Layered Double Hydroxide Hollow Nanocages/Graphene Composite: A Novel Electrode Material with Superior Electrochemical Performance, Chem.-Eur. J., 2017, 23, 14839-14847.

126 Y. Xia, B. Wang, G. Wang and H. Wang, Easy access to nitrogen-doped mesoporous interlinked carbon/NiO nanosheet for application in lithium-ion batteries and supercapacitors, RSC Adv., 2015, 5, 98740-98746.

$127 \mathrm{H}$. Hu, B. Guan, B. Xia and X. W. Lou, Designed formation of $\mathrm{Co}_{3} \mathrm{O}_{4} / \mathrm{NiCo}_{2} \mathrm{O}_{4}$ double-shelled nanocages with enhanced pseudocapacitive and electrocatalytic properties, J. Am. Chem. Soc., 2015, 137, 5590-5595.

128 D. $\mathrm{Yu}, \mathrm{B} . \mathrm{Wu}, \mathrm{L}$. Ge, L. Wu, H. Wang and T. Xu, Decorating nanoporous ZIF-67-derived $\mathrm{NiCo}_{2} \mathrm{O}_{4}$ shells on a $\mathrm{Co}_{3} \mathrm{O}_{4}$ nanowire array core for battery-type electrodes with 
enhanced energy storage performance, J. Mater. Chem. A, 2016, 4, 10878-10884.

129 W. Zeng, L. Wang, H. Shi, G. Zhang, K. Zhang, H. Zhang, F. Gong, T. Wang and H. Duan, Metal-organicframework-derived $\mathrm{ZnO}$ C@ $\mathrm{NiCo}_{2} \mathrm{O}_{4} \quad$ core-shell structures as an advanced electrode for high-performance supercapacitors, J. Mater. Chem. A, 2016, 4, 8233-8241.

130 Y. Dong, Y. Wang, Y. Xu, C. Chen, Y. Wang, L. Jiao and $\mathrm{H}$. Yuan, Facile synthesis of hierarchical nanocage $\mathrm{MnCo}_{2} \mathrm{O}_{4}$ for high performance supercapacitor, Electrochim. Acta, 2017, 225, 39-46.

131 Z. Jiang, Z. Li, Z. Qin, H. Sun, X. Jiao and D. Chen, LDH nanocages synthesized with MOF templates and their high performance as supercapacitors, Nanoscale, 2013, 5, 11770-11775.

132 X. Xu, J. Tang, H. Qian, S. Hou, Y. Bando, M. S. A. Hossain, L. Pan and Y. Yamauchi, Three-dimensional networked metal-organic frameworks with conductive polypyrrole tubes for flexible supercapacitors, ACS Appl. Mater. Interfaces, 2017, 9, 38737-38744.

133 S. K. Meher and G. R. Rao, Ultralayered $\mathrm{Co}_{3} \mathrm{O}_{4}$ for highperformance supercapacitor applications, J. Phys. Chem. C, 2011, 115, 15646-15654.

134 M. Saraf, R. Rajak and S. M. Mobin, MOF derived high surface area enabled porous $\mathrm{Co}_{3} \mathrm{O}_{4}$ nanoparticles for supercapacitors, ChemistrySelect, 2019, 4, 8142-8149.

135 D. Tian, X.-L. Zhou, Y.-H. Zhang, Z. Zhou and X.-H. Bu, MOF-derived porous $\mathrm{Co}_{3} \mathrm{O}_{4}$ hollow tetrahedra with excellent performance as anode materials for lithium-ion batteries, Inorg. Chem., 2015, 54, 8159-8161.

136 R. Ramachandran, W. Xuan, C. Zhao, X. Leng, D. Sun, D. Luo and F. Wang, Enhanced electrochemical properties of cerium metal-organic framework based composite electrodes for high-performance supercapacitor application, $R S C A d v$. , 2018, 8, 3462-3469.

137 Z. Gao, J. Wang, Z. Li, W. Yang, B. Wang, M. Hou, Y. He, Q. Liu, T. Mann and P. Yang, Graphene nanosheet $/ \mathrm{Ni}^{2+} /$ $\mathrm{Al}^{3+}$ layered double-hydroxide composite as a novel electrode for a supercapacitor, Chem. Mater., 2011, 23, 3509-3516.

138 H. Wang and G. Shi, Layered double hydroxide/graphene composites and their applications for energy storage and conversion, Acta Phys.-Chim. Sin., 2018, 34, 22-35.

139 R. Khan, M. T. Mehran, M. M. Baig, B. Sarfraz, S. R. Naqvi, M. B. K. Niazi, M. ZubairKhan and A. H. Khoja, 3D hierarchical heterostructured LSTN@NiMn-layered double hydroxide as a bifunctional water splitting electrocatalyst for hydrogen production, Fuel, 2020, 285, 119174.

140 Y. Li and J. Shi, Hollow-structured mesoporous materials: chemical synthesis, functionalization and applications, Adv. Mater., 2014, 26, 3176-3205.

141 X. Y. Yu, L. Yu and X. W. Lou, Metal sulfide hollow nanostructures for electrochemical energy storage, Adv. Energy Mater., 2016, 6, 1501333.

142 M. T. Mehran and M. M. M. Baig, Metal Sulfide/Mxene Based Nanostructured Electrode Materials for High-
Performance Supercapacitors, ECS Meeting Abstracts, 2019, p. 294.

143 Z. Xiao, Y. Mei, S. Yuan, H. Mei, B. Xu, Y. Bao, L. Fan, W. Kang, F. Dai and R. Wang, Controlled hydrolysis of metal-organic frameworks: hierarchical Ni/Co-layered double hydroxide microspheres for high-performance supercapacitors, ACS Nano, 2019, 13, 7024-7030.

144 Y. Yang, B.-w. Deng, X. Liu, Y. Li, B. Yin and M.-b. Yang, Rational design of $\mathrm{MnO}_{2}$-nanosheets-decroated hierarchical porous carbon nanofiber frameworks as high-performance supercapacitor electrode materials, Electrochim. Acta, 2019, 324, 134891.

145 L. Mai, H. Li, Y. Zhao, L. Xu, X. Xu, Y. Luo, Z. Zhang, W. Ke, C. Niu and Q. Zhang, Fast ionic diffusion-enabled nanoflake electrode by spontaneous electrochemical preintercalation for high-performance supercapacitor, Sci. Rep., 2013, 3, 1-8.

146 A. Pustovarenko, M. G. Goesten, S. Sachdeva, M. Shan, Z. Amghouz, Y. Belmabkhout, A. Dikhtiarenko, T. Rodenas, D. Keskin and I. K. Voets, Nanosheets of Nonlayered Aluminum Metal-Organic Frameworks through a Surfactant-Assisted Method, Adv. Mater., 2018, 30, 1707234.

147 Z. Sui, Z. Chang, X. Xu, Y. Li, X. Zhu, C. Zhao and Q. Chen, Direct growth of $\mathrm{MnO}_{2}$ on highly porous nitrogen-doped carbon nanowires for asymmetric supercapacitors, Diamond Relat. Mater., 2020, 108, 107988.

148 C. Lu, J. Meng, J. Zhang, X. Chen, M. Du, Y. Chen, C. Hou, J. Wang, A. Ju, X. Wang, Y. Qiu, S. Wang and K. Zhang, Three-Dimensional Hierarchically Porous Graphene FiberShaped Supercapacitors with High Specific Capacitance and Rate Capability, ACS Appl. Mater. Interfaces, 2019, 11, 25205-25217.

149 L. Sheng, T. Wei, Y. Liang, L. Jiang, L. Qu and Z. Fan, Vertically Oriented Graphene Nanoribbon Fibers for High-Volumetric Energy Density All-Solid-State Asymmetric Supercapacitors, Small, 2017, 13, 1700371.

150 A. E. Fischer, K. A. Pettigrew, D. R. Rolison, R. M. Stroud and J. W. Long, Incorporation of Homogeneous, Nanoscale $\mathrm{MnO}_{2}$ within Ultraporous Carbon Structures via Self-Limiting Electroless Deposition: Implications for Electrochemical Capacitors, Nano Lett., 2007, 7, 281-286.

151 T. Liu, Z. Zhou, Y. Guo, D. Guo and G. Liu, Block copolymer derived uniform mesopores enable ultrafast electron and ion transport at high mass loadings, Nat. Commun., 2019, 10, 675 .

152 Z. Xu, H. Sun, X. Zhao and C. Gao, Ultrastrong fibers assembled from giant graphene oxide sheets, Adv. Mater., 2013, 25, 188-193.

153 W. Ma, S. Chen, S. Yang, W. Chen, Y. Cheng, Y. Guo, S. Peng, S. Ramakrishna and M. Zhu, Hierarchical $\mathrm{MnO}_{2}$ nanowire/graphene hybrid fibers with excellent electrochemical performance for flexible solid-state supercapacitors, J. Power Sources, 2016, 306, 481-488. 